\title{
RECENT BRYOLOGICAL LITERATURE OF THE FORMER USSR. I.
}

\section{НОВАЯ БРИОЛОГИЧЕСКАЯ ЛИТЕРАТУРА ПО БЫВШЕМУ СССР. 1.}

\author{
IRINA V. CZERNYADJEVA ${ }^{i}$ and MICHAEL S. IGNATOV2 \\ ИРИНА В. ЧЕРНЯДЬЕВА ${ }^{1}$ и МИХАИЛ С. ИГНАТОВ 2
}

Starting from this issue of Arctoa we are going to publish recent bibliography of bryological literature, which either (1) were published on the territory of the former USSR, or (2) deal with floristic and taxonomic investigations on its territory. In the present paper there cited publications which appeared in $1990-1992$, after the "Catalog..., 1986 - 1989" (Afonina, Konstantinova \& Czernyadjeva, 1990) have been published.

ABOLINA, A. A. \& M. LAIVINS 1990. Profesora Nikolaja Maltas devums latviesu dabzinatnel. - [The contribution of profeseor Nikolajus Malta to natural science of Latvia]. Jaunakais Mezsaimnieciba (Riga) 32: $63-78^{3}$.

[ABOLNA, A. A.] АБОЛИНЬ, А. А. 1991 . Мохообразные как строительный материал птичьих гнезд Латвии. - [Bryophytes as a material for nests of birds in Latvija]. Бриолоzия - СССР, еe достихения и перспектива ( Льео, 10-12 сент. 1991) (ред. Демкив, О. Т.), Jboos, AH CCCP, AH YCCP IIn: Demkiv, O.T. (ed.) Briologia v SSSR, ee dostizheniya i perspektivy (Proc. Conf., Lwo, 10-12 Sept. 1991). Lwov, Akad. Nauk SSSR \& Akad. Nauk Ukr. SSRJ: 1217.

[ABRAMOV, 1. I. \& A. L. ABRAMOVA] AEPAMOB, И. И., А. Л. АБРАМОВА 1992. К бриофлоре острова Беннета (Новосибнрские острова). - [On the bryoflora of Bennet Island (Novosibirskie Islands)]. Hosocmu Cucm Huзu. Pacm INovasti Sist. Nizsh Rast.] 28: 134-139.

[ABRAMOV, I. I. \& A. L. ABRAMOVA \& I. V. CZERNYADJEVA] AБPAMOB, Н. Н., А. Л. АБРАМОВА, И. В. ЧЕРНЯЦЬЕВА 1990. Tortula velenovskyi Schiffn. - новый вид с плато Путорана (Среднесибирское тілоскоторье). - [Tortula velenovskyi Schiffn. - a new species from the Putorana Plateau (Central Siberian Highland)]. Hosocmu Cucm. Husu. Pacm. [Novasti Sist. Nizsh. Rast.] 27: $118-125$.

[ABRAMOV, I. I. \& O. M. AFONINA] AGPAMOB, И. И., О. М. АФОНИНА 1990 . О перспективах Бриологических нсследований в ССCP. - IOn
Начиная с этого номера Arctoa, мы намерены публиковать библиографипо новых брнологических работ, хоторне либо (1) были опубликованы на территорин бывшего СССР, либо (2) посвящены флористическим и таксономическим исследованиям на его территории. В настоящий выпуск вошли работы, вышедшие, главным образом, в 1990-1992 г., т.е. после опублихования последнего каталога (Afonina, Konstantinova \& Czernyadjeva, 1990).

vistae of the bryological investigations in the USSR]. Ботаника. Нсследования [Минск] [Botanika. Issledowaniya (Minsk\}) 30: 12-18.

[ABRAMOVA, A. L. \& E. G. NIKOLIN] ABPAMOBA, А. Л., Е. Г. НИКОЛИН 1990. Новое местонахождение Ricciocarpus natans (L.) Corda B Яккутин. - [New locality of Ricciocarpus natans (L.) Corda in Yakutia]. Hosocmu Cucm. Husu. Pacm. [Novosti Sist. Nizsh Rast.] 27: 125-126.

ABRAMOVA, L. I. 1990. Mosses from ground vegetation in Moscow forest parks. - In: Schljakov, $R$. N. (ed.) Abstr. 7th Meeting Centr. \& East Europ. Bryol. Working Group, Kirowk - Apatity, 25-30 June 1990. Apatity, Acad. Sci. USSR, Kola Sci. Center, Polar-Alpine Bot. Garden: 3-4.

[AFONINA, О. М.] АФОНИНА, О. М. 1990. К флоре листостебельных мхов бассейна р. Анадырь. [On moss flora of the Anadyr River Basin]. Hosocmu Cucm. Huзu. Pacm. INowasti Sist. Nizhsh. Rast./ 27: 126-128.

[AFONINA, O. M. \& J. DUDA] АФОНИНА, O. М., П. ДУДА 1992. К флоре печеночных мхов Щентральной м западной Чукотки. - [On the hepatic flora of Central and Westem Chukotkal. Hosocmu Cucm Husu. Pacm. [Nowasti Sist. Nizsh. Rast.] 28. 140-144.

AFONINA, O. M. \& N. A. KONSTANTINOVA 1990 Current bryofloristic exploration of the North of the USSR. - In Schljakov, R. N. (ed.) Abstr. Tth Meeting Centr. \& East Europ. Bryol Working Group, Kirovsk - Apatity, 25-30 June 1990. Apatity, Acad. Sci USSR, Kola Sci. Center, Polar Alpine Bot. Garden: 4-5.

1 - Russia 197376 St.-Petersburg, Prof. Popova, 2, Botanical Institute, Russian Acad. Sci. - Poccug 197376 CahkтПТетербург, проф. Попова, 2, Ботанический институт РАН.

2 - Russia 127276 Moscow, Botanicheskaya, 4, Main Botanical Garden, Russian Acad. Sci. - Poccug 127276. Москва, Ботаническая, 4, Главный ботанический сад РАН.

3 - \{in braces there are notes of the editor\} - \{в фигурных скобках даны замечания редактора) 
[AFONINA, O. M., N. A. KONSTANTINOVA \& I. V. CZERNYADJEVA] AФOHИНA, O. M., Н. A. КОНСТАНТИНОВА. И. В. ЧЕРНЯДЬЕВА 1990. Каталог литературы по мохообразным. отубликованной в СССР. 1986 - 1989. - [Catalog of literature on Bryophytes, published in the USSR. 1986 - 1989]. Anamumb, AH CССP, КНЦ, Полярно-Aльr Боm. Cad /Apatity, Akad. Nauk SSSR, Kol Nauchn Zentr., Polarno-Alp. Bot. Sad J, 51 .

[ANDREJEVA, E. N.] AHДPEEBA, E. H. 1990. Влияние атмосферного загрязнения на моховой покров северо-таежных лесов. - [The influence of air pollution on moss carpet in northern taigal. Лесные экосистемы и атмосферное загрязнение (ред. Arexcee日, В. A.), Л., Наука (In: Alexeev, V. $A$. (ed.) Lesnye ekosistemy i atmosfernoe zagryaznenie. Leningrad, Nauka J: 159-172.

[ANDREJEYA, E. N.] АНДPEEBA, E. H. 1990. Изменение мохово-лишайникового яруса при атмосферном загрязненки. - [Changes in moss and lichen cover under the influence of air pollution]. Влияние промышгенного атмосферного за:рязнения на сосновые леса Кольского nолуострова (ред. Норин, Б. H., B. T. Ярмишко), Л., АН СССР, Бот. Ин-m (In: Norin, B. N. \& V. T. Yarmishko (ed.) Vliyanie promyshlennogo atmosfernogo zagryazneniya na sosnovye lesa Kolskogo Poluostrova. Leningrad, Akad. Nauk. SSSR, Bot. Inst. J: 131-140.

ANDREJEVA, E. N. 1990. The new type of bryophyte life cycle in the industrial air pollution regions. - In: Schljakov, R. N. (ed.) Abstr. 7th Meeting Centr. \& East Europ. Bryol Working Group, Kirousk - Apatity, 25-30 June 1990. Apatity, Acad. Sci. USSR, Kola Sci. Center, Polar-Alpine Bot. Garden: 5-6.

[ANONYMOUS] AHOHИM 1991. Андрій Созонтович Лазаренко. - [Andrij Sozontovicz Lazarenko]. Бриология в СССР, ее достижения и

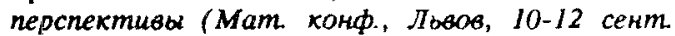
1991) (ред. Демкия, О. Т.), Львов, АН СССР, AH YCCP IIn: Demkiv, O. T. (ed.) Briologia $v$ SSSR, ee dostizheniya i perspektivy (Proc. Conf., Lrov, 10-12 Sept. 1991). Lwov, Akad. Nauk SSSR \& Akad. Nauk Ukr. SSR ]: 3-11.

ARISKINA, N. P. 1990. Kazan botanists' bryological studies. - In. Schljakov, R. N. (ed.) Abstr. 7th Meeting Centr. \& East Europ. Bryol Working Group, Kirousk - Apatify, 25-30 June 1990. Apatity, Acad. Sci. USSR, Kola Sci. Center, PolarAlpine Bot. Garden: 7.

AVETISYAN, M. S. \& B. I. DILDARYAN 1990. Materials the florn of moss of steppe coenosis in some regions of Northern Armenia. - In: Schljakov, R. N. (ed.) Abstr. 7th Meeting Centr. \& East Europ. Bryol. Working Group, Kirovsk - Apatity, 25-30 June 1990. Apatity, Acad. Sci. USSR, Kola Sci. Center, Polar-Alpine Bot. Garden: 8.

[BAIK, О. L.] БAIK, О. Л. 1990. Морфофізіологічна та біохімічня характеристика поліллоіднопо ряду Amblystegium serpens (Hedw.) B. S. G. [Morphophysiological and biochemical characteristics of a polyploid series Amblystegium serpens (Hedw.) B. S. G.]. Укр. Бот. Журн. [Ukr. Bot. Zhurn] $47(6): 46-49$.
BAIK, O. L. 1990. Morphological and biochemical traits of the genetic differentiation of the chromosome races of mosses. - In. Schljakov, $R$. N. (ed.) Abstr. 7th Meeting Centr. \& East Europ. Bryol. Working Group, Kirovk - Apatity, 25-30 June 1990. Apatity, Acad. Sci. USSR, Kola Sci. Center, PolarAlpine Bot. Garden: 9.

[BAIK, О. І.] БАIK, О. Л. 1991. Внутривидовые морфофизиологические разиичия между хромосомными расами мхов. - IInfraspecific morphophysiological differences between chromosome races of mosses]. Бриолоzия в CCCP, ee достижения и перспективы (Мат конф., Львов, 10-12 сент. 1991) (ред. Демкив, О. Т.), Львов, AH CCCP, AH YCCP IIn: Demkiv, O.T. (ed.) Briologia v SSSR, ee dostizheniya $i$ perspektivy (Proc. Conf., Lwov, 10-12 Sept. 1991). Lwov, Akad. Nauk SSSR \& Akad. Nauk Ukr. SSR]: 18-22.

[BAIK, O. L.] БAIK, О. Л. 1991. Особливості формування хромосомных pac Funaria hygrometrica Hedw. - [The peculiarities of formation of the chromosomal races of Funaria hygrometrica Hedw.]. Актуальні проблеми виөчення фітобіоти західних регіонів Украіни (Мат. Конф., Львів, 2-5 квімия 1990) (ред. Кагало, О.О., Н. М. Сичак)Львів, Льњiв. Вid. Iн-my Бот. АН УРСР, Ibsiв. Дepж. Ун-m IIn: Kagalo, O. O\& N. M. Sychak (ed.). Aktualni problemy vyvchennya fitobioty zakhidnykh regioniv Ukrainy (Proc. Conf., Lviv, 2-5 Apr. 1990) Lviv, Lviv. Vid. Inst. Bot. Akad. Nauk Ukr. RSR \& Lviv. Derzh. Univ. J: 5-7.

[BAIK, O. L., R. T. RIPETSKY \& I. S. DANILKIV] БАІК, О. Л., Р. Т. РІПЕЦКИЙ, І. С. ДАНИЛКІВ 1990. Морфофізіологічний аналіз хромосомных pac та апоспоричних поліплодів моху Amblystegium serpens (Hedw.) B. S. G. - IMorphophysiological analysis of chromosome races and aposporic polyploids of moss Amblystegium serpens (Hedw.) B. S. G.]. Укр. Бот. Журн. [Ukr. Bot. Zhurn.] $47(1)$ : 52-57.

[BARDUNOV, L. V.] БАРДУНОВ, Л. В. 1990. Восточноазиатские виды во флоре мхов Южной Сибири. - [East-Asian species in moss flora of South Siberia]. Eom Журн. [Bot. Zhurn.] 75(5): $636-643$.

[BARDUNOV, L. V.] БАРДУНОВ, Л. В. 1990. Мохообразные. - [Mosses]. Уникальные объекты жиєой природы бассейна Байкала (ред. Попов, $I$. B.), Hoвocuбирск, Наука (In. Popov, L. V. (ed.) Unikalnye ob'ekty zhivoj prirody basseina Baikala. Nowsibirsk, Nauka J: 49-50.

BARDUNOV, L. V. 1990. East Asiatic species in the moss flora of Siberia. - In: Schljakov, R. N. (ed.) Abstr. 7th Meeting Centr. \& East Europ. Bryol. Working Group, Kirovk - Apatity, 25-30 June 1990. Apatity, Acad. Sci. USSR, Kola Sci. Center, Polar-Alpine Bot. Garden: 10.

[BARDUNOV, L. V.] БАРДУНОВ, Л. В. 1992. Очерк бриофлоры Сибири. - [A review of bryoflora of Siberia]. Hoвocuбupck, Hayka [Nowosibirsk, Nauka]: 96

[BARDUNOV, L. V., S. K. GAMBARYAN \& V. YA. CHERDANTSEVA] БAPДУНOB, Л. B., C. K. ГАМБАРЯ્ЯН, В. Я. ЧЕРДАНЦЕВА 1991. Мохообразные. - [Bryophytes]. Флора, мико- $и$ 


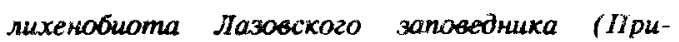
морский край) (ред. Азбукина 3. М.), Braduocmw, АН СССР, ДВВ, Биол-Поча Инт ¿ Jasosckuй Го. Zanosedrux IIn: Azbukina, Z. M. (ed.) Flora, myco i likhenobiota Lazowsogo zo povednika (Primorskij Kraj). Vladiwostok, Akad Nouk SSSR,Delnewast. Otd.,Biol Pocho inst. \& Lazowsil Gos. Zapov. ]: 35-60.

[BARDUNOV, L. V. \& U. K. MAMATKULOV] БАРДУНОВ, Л. В., У, К. МАМАТКУЛОВ 1991 Географо-генетические элемекты брнсфлоры CCCP. - [Zonal elements of bryoflora of the USSR]. вриология a СCCP, еe docmuжения nерспективы (Mam конф., Jlbos, 10-12 сент 1991) (ред. Демкив, О. Т.), Львов, АН СССР, AH YCCP IIn: Demkiv, O. T (ed.) Briologia y SSSR, ee dostizheniya $i$ perspektivy (Proc. Conf., Lvov, 10-12 Sept. 1991). Lwov, Akad. Nauk SSSR d Akad. Nauk Ukr. SSR]: 23-26.

BELKINA, O. A. 1990. Andreaea blytii Schimp. in Murmansk Region, USSR. - In Schljakov, $R$. N. (ed.) Abstr. 7th Meeting Centr. \& East Europ. Bryol Working Group, Kirousk - Apatity, 25-30 Iune 1990. Apatity, Acad. Sci. USSR, Kola Sci. Center. Polar-Alpine Bot. Garden: 80.

BOBORAJABOV, B. 1990. The hepatics of Middle Asia. - In: Schljakov, R. N. (ed.) Abstr. 7th Meeting Centr. \& East Europ. Bryol. Working Group, Kirows - Apatity, 25-30 June 1990. Apatity, Acad. Sci USSR, Kola Sci. Center, Polar-Alpine Bot. Ganden: 11 .

[BOBORAJABOV, B.] БOБОРАДЖАБОВ, Б. 1991. Мохообразные Памира. - [The bryophyia of Pamir]. Бриология а СССР, еe достижения и перспективы (Mam. конф., Львав, 10-12 сент. 1991) (реt. Демкив, O. T.), JbaOs, АН СССР, AH YCCP (In: Demkiy, O. T. (ed.) Briologia y SSSR, ee dostizheniye $i$ perspektivy (Proc Conf., Lvov, 10-12 Sept. 1991). LWov, Akad. Nauk SSSR \& Akod. Nauk Ukr. SSRJ: 27-30.

BOCZ, M. S. 1990. Rhytmical Pattern in Sphagnum mosses annual increment in Ladoga Region near Leningrad (USSR). - In: Schljakov, R. N. (ed.) Abstr. 7th Meeting Centr. \& East Eump. Bryol. Working Group, Kirowsk - Apaity, 25-30 June 1990. Apatity, Acad. Sci. USSR, Kola Sci. Center, Polar-Alpine Bot. Garden. 12.

[BOCZ, M. S. \& E. O. KUZMINA] БOЧ, M. C., E. O. КУЗЬМИНА 1991. O сфагновњ мхах noлyострова Kaм4atka. - [On Sphagna of Kamchatka Peninsula]. Spuororus a CCCP, ee достихекия и перспективы (Mam. конф., Пь⿻о一, 10-12 сен. 1991) (реd. Денкік, O. T), Jbecs, AH CCCP, AH YCCP (In Denkiv, O. T. (ed.) Briologia v SSSR, ee dostizheniya i perspektivy (Proc. Conf., Lwov, 10-12 Sept. 1991). LWov, Akad. Nauk SSSR \& Akad. Nauk Ukr. SSR j: 35-38.

[BOIKO, M. F.] БOИKO, М. Ф. 1990. Мохообразные в первичных сукщесснях на промышленных отвалах в степной зоне. - (Bryophytes in primary successions on industrial dumps in steppe zonel. Промышиенная ботанита - состояние и перспективы развития. Тез докл конф., Донецк, сент., 1990 (реб. Тарабрин, В. Н.), Kuеs, Наукава Думка (In: Tarabrin, V. P. (ed.) Promyshlennaya Botanika - sostoyanie i perspektivy razvitiya (Abstr. Chal, bonst. Sepi, 1990). Kiev Naukova Dumkal: $55-56$.

[BOIKO, M. F.] БOИKO, M. Ф. 1990. Жниненные циклш мохообразиых степной зоқы. [Life cycles of bryophytes in steppe zone]. Bwar Hayku [Biol Nauki) $(12): 82-87$

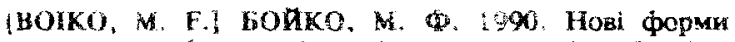
Moxonozínux. - [Now forms of bryophytes]. Укp. Bom Xypu /Ukr. Bot. Zhum i 47(1):94-95.

[BOIKO, M. F.] boमkKO, M. Ф. 1990. Типы жизненных скатепй 由охообразных степной 3оны. - [Types of life strategies of bryophyles of the steppe zone]. Bom Kyph (Bot. Zhum, 75(12): 1681.1689.

[BOIKO, M. F.] EOHXO, A. क. 1991

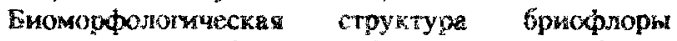
crenной зоны. - [Biontorghological smucture of bryoflore of steppe zone?. Bhow Max. O-ea Hcnbm. ITpup. Omd. Buan (Buli. Mast Goshch Ispyt. Prir. Otd. Biod i $96(3): 18-124$.

[BOIKO, M. F.] EGHKO, M. Ф. 1991. Мохообазные начальных стадий перннчаља сукијесскй на субстратах антропогенного пронсжождення. [Bryophytes of first stages of primary successions of anthropogenic substrates]. Ikonozus [Ekclogia)(2): 21-25.

[BOIKo, M. F.] 6оһкKO, M. 1991. Редкие виды бриофлоры стегной јоны европейской части CCCP. - [Rare species of bryophytes in steppe zone of European Part of the USSR]. Bom. ЖKурн. [Bot. Zhurn] 7615): $759-766$.

[BОІКО, М. F.] БОИКО, М. Ф. 1991. Помовые типы мохообразных степной зоны. - ISexual types of bryophytes in sieppe zone]. \$yph O6w Бsox. [Zhurn. Obshch Biol] $52(2): 214-221$.

[BOLKO, M. F.] БоR̆KO, M. 4. 1991. Некоторье acneкты sнализа таксономичесхон струхтуры брмофлоры степной зоны. - [Some aspects of analysis of taxonomic sinucture of bryoflora of steppe zonel. Бpuonozus CCCP, ee zocmuxenus $u$

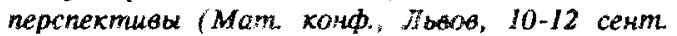
1991) (ред. Демхив, O. T.), ILtos, AH CCCP, AfI YССP IIn: Denkiv, $O$. $x$. (ed.) Briologia y SSSR, ee dastisheniya i perspektivy (Proc. Conf. Lwov, 10-12 Sept. 199 I). LWov, Akad. Nawk SSSR \& Akad. Nauk UkF. SSRI: $2:-34$.

[BOIKO, M. F. L, YA. PARTYKA] BOHKO, M. Ф.

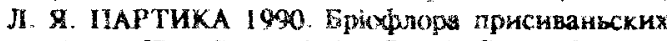
crenia. "[Bryoflor of the Sivash Steppes]. Yxp. Bom Xypt. IUkr. Bot. Zhwor/ $7(2): 13-16$

[BOLYUKH, Y. A.] BOJKX, B. A. 1990. Cравиекห бриорлор основных оротрафических районов центральной части Подолин. - IComparison of bryofloras of the main orographic regions on Cenura! Part of Podolia [Ukraine]]. Akmyanonibe sonpocis ботакики "в экологин. (Тез рокл конф., Каменец-Подольский, 14-16 мая 1990) Канене4IIodorbckuй lAktualnye woprosy botaniki i ekologii (Abstr. Con,. Kamencz-Podolskii, 14-16 May 1990). Kamenez-Podolskiil: 29.

[BOLYCKH, V. А.] БолКОХ, В. А. 1991. Мохоподібні г. "Гостра скеля" (пам'ятка прмроди місцевого значенма). - [Bryophytes of the Regional Resefve "Gostra Skelya"]. Aкmуапьні проблени виачення 
фimoбiomи західних регіонів Украіни (Mат. Конф., Льяiє, 2-5 хвімня 1990) (ред. Кагало,

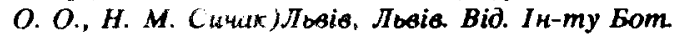
AH УРCP, Jboie. Дepג Yk-m [In: Kagalo, O. $O$ \& N.M. Sychak red.). Aktualni problemy vyuchennya fitobioty zakhidnykh regioniv Ukrainy Proc. Conf., Lviv, 2-5 Apr. 1990) Lviv, Lviv. Vid. Inst. Bot. Akad. Nauk Ukr. RSR \& Lviv. Derzh. Univ. J: 8-10.

[BOLYUKH, V. А.] БОЛЮХ, В. А. 1992. Бриофлора центряльной части Подолии и ее анализ. [Bryollora of Central Part of Podolia and its analysis \{Ukraine\}]. Aвmopeф. . канб. Guor наук Киев, AH УССР, Ин-m Gomaruки Ph. D. Thesis. Kiev, Akad. Nauk Ukr. SSR, Inst. Bot. J, 20.

[BULYCHEV, А. А.] БУЛЫЧЕВ, А. А. 1990. Фотоиндуцированные потенцивлы действня в клетках зеленьх растений. - [Plant induced action potentials in cells of green plants]. Мембранный транспорт и аиолектрическая активность растений (ред. Onрuтюв, В. А. и др.) Горький, Гopbk. Гoc. YH-m IIn: Opritov, V.A. \& al (eds.) Membrannyi transport and bioelektricheskaya aktivnost rastenij. Gorkiy, Gork. Gos. Univ. J: \&-12.

[BULYCHEV, A. A. \& D. REMISH] БУЛЫЧЕB, A. A., Д. РЕМИШ 1991. Временное подавлекие Н+насоса плазмалеммы Anthoceros после световых вспышек секундной длительности. - [Temporary supression of H+-pump of plasmalemma of Anthoceros after light flashes of the secund lenth]. Фuзuor Pacm [Fisiol Rast.] 38(3): 499-506.

CHABAN, K. I. 1990. Intraspecific polyploid series of moss Pohlia nutans (Hedw.) Lindb. - In: Schljakov, R. N. (ed.) Abstr. 7th Meeting Centr. \& East Europ. Bryol Working Group, Kirovsk - Apatity, 2530 June 1990. Apatity, Acad. Sci. USSR, Kola Sci. Center, Polar-Alpine Bot. Garden: 13.

[CHABAN, K. I.] ЧАБАН, Х. I. 1991. Вплив кліностатування на ультраструктуру листовидних пластинок тетафіса прозорого. - [Effect of clinostation on the fine structure of the leaf plates of Tetraphis pellucida Hedw.]: Ахmуальні проблеми вивиення фітюбіоти західних реzіонів Украіни (Маm Конф., Львів, 2-5 хвітня 1990) (ред. Каzало, О. О., Н. М. Сичак)Лbsie, Jbsia. Bid. Iн-

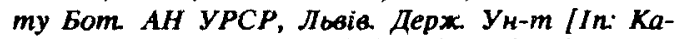
galo, $O . O$ \& N. M. Sychak (ed.). Aktualni problemy vyuchennya fitobioty zakhidnykh regioniv Ukrainy (Proc. Conf., Lviv, 2-5 Apr. 1990) Lviv, Lviv. Vid. Inst. Bot. Akad. Nauk Ukr. RSR \& Lviv. Derzh. Univ. ]: 120-122.

[CHERDANTSEVA, V. YA.] ЧEPДAHЦЕBA, B. 9 . 1990. О6зор семейства Thuidiaceae Дальнего Bocroka CCCP. - IA review of the family Thuidiaceae on Far East of USSR]. Криптоzaмuческие исследования на Дальнем востоке (ред. Васильева, Л. Н. и др.), Владивасток, АН СССР, ДBO IIn: Vasiliewa, L. N. \& al (ed.) Kriptogamicheskie issledoraniya na Dalnem Vostoke. Vladiwstok, Akad Nauk SSSR, Dalnewast. Otd.J: 149-157.

[CHERDANTSEVA, V. YA.] ЧЕРДAHЦЕВA, В. Я. 1990. Материаль К брнофлоре Хинганскопо заповедника. - [Contributions to the bryoflora of Khingan Reserve]. Криптоганические исстедраания на Дальнем востоке (ред.
Bacurbesa, Л. Н. и др.), Вradusocmox, АH CCCP, ДВО (In: Vasilieva, L. N. \& al. (ed.) Kriptogamicheskie issledovaniya na Dalnem Vastoke. Vladivastok, Akad. Nauk SSSR, Dalnewost. Otd.J: 171-178.

CHERDANTSEVA, V. YA. 1990. The family Thuidiaceae in Bryoflora of the Soviet Far East. - In: Schljakov, R. N. (ed.) Abstr. 7th Meeting Centr. \& East Europ. Bryol Working Group, Kirows - Apatity, 25-30 June 1990. Apatity, Acad. Sci. USSR, Kola Sci. Center, Polor-Alpine Bot. Garden: 14.

[CHERDANTSEVA, V. YA.] ЧЕРДAНЩЕВA, В. Я. 1991. Вклад А. С. Лазаренко В изучение бриорлоры юга Советского Дальнего Востока. [Contribution of A. S. Lazarenko to knowledge of bryoflora of south of Soviet Far East]. Bpuanozur 6 СССР, еe достихения $u$ перспективы (Маm. конф., Льео, 10-12 сент. 1991) (ред. Демкив, O. T.), J Jo00, AH CCCP, AH YCCP (In: Demkiv, O. T. (ed.) Briologia vSSSR, ee dostizheniya $i$ perspektivy (Proc. Conf., Lwov, 10-12 Sept. 1991). Lwov, Akad. Nauk SSSR \& Akad. Nauk Ukr. SSRI: 196-200.

[CHEREPANOV, I. V.] ЧЕРЕПАНОВ, И. В. 1990. Соббества мохообразных на ранних стадиях зарастания обнаженных песчаников. - [Bryophyte communities on early stages of successions on bare sandstones]. Биол мауки [Biol Nauki] (4): 74-77.

CHEREPANOVA, L. A. 1990 . Dynamic of moes cover formation in pine stands. - In Schljakov, $R$. $N$. (ed.) Abstr. 7th Meeting Centr. \& East Europ. Bryol. Working Group, Kirovsk - Apatity, 25-30 June 1990. Apatity, Acad. Sci. USSR, Kola Sci. Center, Polar-Alpine Bot. Garden: 15-16.

[CZERNYADJEVA, I. V.] ЧЕРНЯДЬEBA, И. В. 1990. Бриофлора северо-запада плато Путорана. [Bryoflora of North-West of Putorana Plateau]. Hooocmu Cucm. Huзu. Pacm [Nowasti Sist. Nizsh. Rast.] 27: 153-157.

CZERNYADJEVA, I. V. \{CHERNYADYEVA\} 1990. Peculiarities of moss flora of North-West of the Putorana Plateau. - In. Schljakov, R. N. (ed.) $A b-$ str. 7th Meeting Centr. \& East Europ. Bryol Working Group, Kirowsk - Apatity, 25-30 June 1990. Apatity, Acad. Sci. USSR, Kola Sci. Center, Polar-Alpine Bot. Garden: 16.

[CZERNYADJEVA, I. V.] ЧЕРНЯДЬЕВA, Н. В. 1992. Анализ активности видов бриофлоры северозапада плато Путорана. - [Analysis of species activity in bryoflora of North-West of Putorana Plateau]. Hooocmu Cucm. Huзu. Pacm. [Novosti Sist. Nizsh. Rast.J 28: 161-165.

[CZERNYADJEVA, I. V.] ЧEPHЯДЬEBA, И. В. 1992. К бриофлоре архипелага Земля Франца-Косифа. - [On the bryoflora of Zemlya Frantza Josefa Archipelagol. Hosocmu Cucm. Husus Pacm. [Nowosti Sist. Nizsh Rast.] 28: 156-16I.

CZERNYADJEVA, I. V. \& M. S. IGNATOV 1991 . Pohlia andrewsii J. Shaw in the U. S. S. R. - J. Bryol 16(4): 581-587.

CHIKOVANI, N. V. 1990 . On the geography of musci for open habitats of Georgia. - In: Schljakov, R. N. (ed.) Abstr. 7th Meeting Centr. \& East Europ. Bryol Working Group, Kirowk - Apatity, 25-30 
June 1990. Apatity, Acad. Sci. USSR, Kola Sci. Center, Polar-Alpine Bot. Garden: 17.

CHORKAVTSIV, YA. D. 1990. Morphogenesis of the gametophytes of Tetraphis pellucida. - In: Schljakov, $\boldsymbol{R}$. N. (ed.) Abstr. 7th Meeting Centr. \& East Europ. Bryol. Working Group, Kirowsk - Apatity, 2.5-30 June 1990. Apatity, Acad. Sci. USSR, Kola Sici. Center, Polar-Alpine Bot. Garden: 18

DANIELS, F. J. A. 1990. Sphagnum-rich plant communities of Southeast Greenland. - In Schljakov, $R$. N. (ed.) Abstr. 7th Meeting Centr. \& East Europ. Bryol Working Group, Kirousk - Apatity, 25-30 June 1990. Apatity, Acad. Sci. USSR, Kola Sci. Center, Polar-Alpine Bot. Garden: 19.

DANIL.KIV, I. S. 1990. The general results of karyological investigation of mosses from USSR. - In. Schljakov, R. N. (ed.) Abstr. 7th Meeting Centr. \& East Europ. Bryol Working Group, Kirousk - Apatity, 25i-30 June 1990. Apatity, Acad. Sci. USSR, Kola Sci. Center, Polar-Alpine Bot. Ganden. 20.

[DANILKIV, I. S.] ДАНИЛКИВ, И. С. 1991. Полиплондия в таксономических группах Moxoo6pa3нwix. - [Polyploidy in taxa of bryophytes]. Бриология в СССР, ее достихения и перспективы (Мат. конф., Львов, I0-12 сент. 1991) (ред. Демкив, O. T.), ЛЬАОА, АН СССР, AH YCCP IIn: Demkiv, O. T. (ed.) Briologia y SSSR, ee dostizheniya i perspektivy (Proc. Conf., Lwov, 10-12 Sept. 1991). Lwov, Akad. Nauk SSSR \& Akad. Nauk Ukr. SSR ]: 60-65.

DEMKIV, O. T. 1990. Dynamical structure of successive steps of the moss gametophyte morphogenesis. - In: Schljakov, R. N. (ed.) Abstr. 7th Meeting Centr. \& East Europ. Bryol Working Group, Kirousk - Apatity, 25-30 June 1990. Apatity, Acad. Sci. USSR, Kola Sci. Center, Polar-Alpine Bot. Garden: 21.

[DEMKIV, О. T.] ДЕМКИВ, О. Т. 1991. Ответные реахции мхов на загрязнение внешней среды. [Responses of mosses on environmental pollution]. Бриология в СССР, ee достихения и перспективы (Мат. конф., ЛЬвая, 10-12 сент. 1991) (ред. Демкив, О. Т.), ЛЬвов, АН СССР, AH YCCP IIn. Demkiv, O. T. (ed.) Briologia $v$ SSSR, ee dostizheniya i perspektivy (Proc. Conf., Lrov, 10-12 Sept. 1991). Lrov, Akad. Nauk SSSR \& Akad. Nauk Ukr. SSR]: 66-69.

[DEMKIV, О. Т.] ДЕМКИВ, О. Т. 1991. Вклад А. С. Лазаренко в развитие экспериментальной бриология. - [The contribution of A. S. Lazarenko to development of experimental bryology]. Бриология в СССР, ее достихения $u$ nерспективе (Мат. конф., Лlьво, 10-12 сент. 1991) (ред. Демхия, О. Т.), ЛЬо0в, АН СССР, AH YCCP (In: Demkiv, O. T. (ed.) Briologia $v$ SSSR, ee dostizheniya $i$ perspektivy (Proc. Conf., Lwov, 10-12 Sept. 1991). Lwov, Akad. Nauk SSSR \& Akad. Nauk Ukr. SSRJ: 70-74.

[DEMKIV, О. Т.] ДЕМКИВ, О. Т. 1992. Динамика формообразовательных процессов гаметофита Mxa. - [Dynamics of morphogenetic processes of moss gametophyte]. Teз. Докл. 2 Съeзda Bcec. $O$ фа физиологов растений, Ч. ІІ, Минск, 24-29 сенm. 1990 М., АН СССР, Всес. О-во Физиол. Pacm lAbstr. 2 Congr. of All-Union Soc. Plant Physiol. Pt. II, Minsk, 24-29 Sept. 1990. Moscow,
Akad. Nauk SSSR, Vses. Obshch. Fiziol Rast.]: 63.

[DEMKIV, O. $T$. ., O. R. KARDASH \& YA. D. KHORKAVTSIV] ДЕМKIB, $0 . \quad$ T., 0 . $P$. КАРДАШІ, Я્ર. Д. ХОРКАВЦІВ 1992. Морфогенез протонеми Funaria hygrometrica Hedw.. [Morphogenesis of protonema of Funaria hygrometrica Hedw.]. Укp. Bom. Хурн. [Ukr. Bot. Zhurn] 49 (4): $70-75$.

[DEMKIV, O. T., A. R. KARDASH \& Z. I. MAMCHUR] ДЕМКИВ, О. Т., А. Р. КАРДАІІ, 3. И. МАМЧУР 1991. ВнУтривкдова изменчивость и адаптационные потенцим различных видов листостебельных мхов. - [Intraspecific variation and adaptation potency of different moss species]. Lumorozus [Citologia] 33(5): 98.

[DEMKIV, O. T., YA. D. KHORKAVTSIV \& A. R. KARDASH] ДЕМКИВ, О. Т., Я. Д. ХОРКАВЦИВ, А. Р. КАРДАШ 1991. Полярность и клеточная дифференцировка в процессе развитня архегониальных растений. - [Polarity and cell differentiation in development of archegonial plants]. Aналитинеские acnexmo дифференцировки (ред. Пресноs, Е. В. и др.) М., Hayxa I In: Presnov, E. V. \& al. (eds.) Analiticheskie aspekty differenzirovki. Moscow, Nauka]: 12I132.

[DEMKIV, O. T., YA. D. KHORKAVTSIV \& O. R. KARDASH] ДEMKIB, О. Т., Я. Д. ХОРКАВЦІВ, О. Р. КАРДАІІ 1992. Організація михрофібрил целюлози у процесі росту протонемн мохів. [Organization of cellulose microfibrills in the process of moss protonema growth]. Укp. Bom. Журк. [Ukr. Bot. Zhurn] $49(3): 51-56$.

DILDARIAN, B. I. \& K. G. AVAKIAN 1990. The moss participation in different plant formations of Tsahkunjats and Techenys Ridges in Armenian SSR. - In: Schljakov, R. N. (ed.) Abstr. 7th Meeting Centr. \& East Europ. Bryol. Working Group, Kirovsk - Apatity, 25-30 June 1990. Apatity, Acad. Sci. USSR, Kola Sci. Center, Polar-Alpine Bot. Garden: 22-23.

DRUZHININA, O. A. 1990. Bryophytes in the USSR Red Data Book. - In Schljakov, R. N. (ed.) Abstr. 7th Meeting Centr. \& East Europ. Bryol Working Group, Kirovk - Apatity, 25-30 June 1990. Apatity, Acad. Sci. USSR, Kola Sci. Center, PolarAlpine Bot. Garden: 23-24.

[DRUZHININA, О. А.] ДРУХИНИНА, О. А. 1991. Состояние и перспективы охраны редких вкдов бриофлоры СССР. - ICurrent status and perspectives of protection of rare species of bryofiora of the USSR]. Бриология в СССР, еє достихения и перспехтивы (Мат. конф., ЛЬөов, 10-12 сент. 1991 ) (ред. Демкия, O. T.), Льsos, АH СССР, AH YCCP IIn: Demkiv, O. T. (ed.) Briologia v SSSR, ee dostizheniya $i$ perspektivy (Proc. Conf., Lwov, 10-12 Sept. 1991). Lwov, Akad. Nauk SSSR d Akad. Nauk Ukr. SSR ]: 75-83.

DURING, H. J., H. van RUNBERK \& B. F. van TOOREN 1990. Pattern and dynamics of bryophytes in relation to their life strategies. - In: Schljakov, $R$. N. (ed.) Abstr. 7th Meeting Centr. \& East Europ. Bryol Working Group, Kirowsk - Apatity, 25-30 June 1990. Apatity, Acad. Sci. USSR, Kola Sci. Center, Polar-Alpine Bot. Garden: 24. 
[DYACHENKO, А. Р.] ДЬЯЧЕНКО, А. П. 1990. Новые цлх Среднего Урала находки листостебельных мхов. - [New for Middle Ural records of mosses]. Эколого-фropистические исследования по споробым растениям Урала (реd. Горчакоеский, II. Л.), Сеepdroscк, AH CCCP, YpO IIn: Gorchatowsky, $P$ L (ed.) Ekologo-floristicheskie issladovaniya po sporovym rasteniyam Urala Swendlows, Akad. Nauk SSSR, Ural. Otd.J: 19-23.

[DYACHENKO, А. Р.] ДЬЯЧЕНКО, А. П. 1991. Исторня кзучения и нехоторые особенности флоры листостебельных мхов Приполярного Ypasa. - [History of studies and some peculiarities of moss flora of Cis-Polar Urall. Бриолоzus $\theta$ СССР, достихения и перспективы (Mam. комф., Львов, 10-12 сент. 1991) (ред. Демкив, o. T.), Jo608, AH CCCP, AH YCCP /In-Demkiv, O. T. (ed.) Briologia v SSSR, ee dostizheniya i perspektivy (Proc. Conf., Lwov, 10-12 Sept. 1991). Lwov, Akad. Nauk SSSR \& Akad. Nauk Ukr. SSR]: 84-86.

[FARRA, S. M.] ФAPPA, C. M. 1991. Сравнительная анатомия и ультраструктура стеблей гаметофитов листостебельнімх мхов Сирия. - [Comparative anatomy and ultra-structure of stems of mosses of Syria]. Aomopeф. дисс.. канд. биол наук M., MIY [Thesis Ph. D.. Moscow, Mosk. Gos. Univ.], 22.

[FILATOVA, Y. R., YU. S. PROZOROVA \& A. G. NOVOROZKAYA] ФHJATOBA, B. P., K. C. ПРО3ОРОВА, А. Г. НОВОРОЦКАЯ 1989. Влияние концентрации биогенных злементов в питательных растворах на рост сфагновых мхов в водных культурах. - IInfluence of concentration of biogenic elements in nutrient solution on growth of Sphagna in solution conditions]. Pесypca 6оrom СССР u nути ux использования (реd. вомперский, С. 9., Ю. С. Прозоров) (Мат. 9 Всес семинара-эхскурсии, Хабаровск, 1986) Xабароock, AH CCCP, ДBO IIn: Vomperskij, S. Ae. \& Yu. S. Prozorov (ed.) Resursy bolot SSSR $i$ puti ikh ispolionaniya (Proc 9 Vses. Symp.-Excursion, Khabarows, 1986) Khabarows, Akad. Nauk SSSR, Dalnewast. Otd.]: 138-144.

FUESTES, E. \& A. R. BURGAZ 1990. Bryo-lichenic epiphytic vegetation on decidous forest from La Riona (NE-Spain). - In: Schljakov, R. N. (ed.) Abstr. 7th Meeting Centr. \& East Europ. Bryol. Working Group, Kirows - Apatity, 25-30 June 1990. Apatity, Acad. Sci USSR, Kola Sci. Center, PolarAlpine Bot. Garden: 25.

[GAMBARYAN, S. K.] ГАMБAPЯH, C. К. 1990. История изучения печеночных мхов Дальнего Bocroka. - [History of studies of hepatics of the Far East]. Криптогамические исследования на Дальнем Востоке (ред. Васильева, Л. Н. и др.), Bradurocmoк, АH CССP, ДBO /In: Vasilieva, $L$ N. \& al (ed.) Kriptogamicheskie issledowaniya na Dalnem Vostcke. Vladiwostok, Akad. Nauk SSSR, Dalnevost. Otd. I: 141-148.

[GAMBARYAN, S. K.] ГAMБAPGH, C. K. 1990. Новые и редкие для СССР печеночные мхи. [New and rare hepatics for the USSR]. Криптогажические исследования на Дальнем востоке (ред. васкльева, Л. Н. и др.),
Bradueacmox, AH CCCP, ДВВO (In: Vasiliewa, $L$ N. \& al. (ed.) Kriptogamicheskie issledowaniya na Dalnem Vostoke. Vladiwastok, Akad, Nauk SSSR, Dalnevast. Otd. J: 149-157.

GAMBARYAN, S. K, 1990. On the hepatic flora of South Primorye Territory (USSR). - In: Schljakov, R. N. (ed.) Abstr. 7th Meeting Centr. \& East Europ. Bryol. Working Group, Kirousk - Apatity, 25-30 June 1990. Apatity, Acad. Sci. USSR, Kola Sci. Center, Polar-Alpine Bot. Garden: 25-26.

[GAMBARYAN, S. K.] ГAMGAPY्रH, C. K. 1991. Матерналы х флоре печеночных мхов Coвercxoro Дальнего Востока. - [Contribution to flora of hepatics of Soviet Far East]. Бpuorozus a CCCP, ee достихения и перспективы (Мат. конф., Л Лsob, 10-12 сент. 1991) (ред. Демкив, О. Т.), Львов, AH CCCP, AH YCCP (In: Demkiv, O. T. (ed.) Briologia v SSSR, ee dostizheniya $i$ perspektivy (Proc. Conf., Lwov, 10-12 Sept. 1991). Lwov, Akad. Nauk SSSR \& Akad. Nauk Ukr. SSRJ: 52-55.

[GAMBARYAN, S. K.] ГАМБAPЯH, C. K. 1991. O фrоре печеноных мхов заповедников Южного Приморья, - [On the hepatic flora of the reserves of South Primorye Territory]. Bradueocmok, $A H$ СССР, ДВО, Биол-Поче Ин-т. Деп. ВНННТИ 12. XII. 1991, No 4596-B9I IVladivostok, Akad. Nauk SSSR, Dalnewost. Otd., BioL-Pochv. Inst. Msc. Reserved VINITI 12. XII. 1991, No 4596B91.J, 15 .

[GAMBARYAN, S. K.] ГAMБAPЯH, C. K. 1992. Антоцеротовые и печеночники Южного Приморьs. - [Anthocerotae and Hepaticae of Southern Primorye]. Bradueocmox, PAH, $Д B O$, Биол-Поче. Ин-m [Vladivastok, Rass. Akad. Nauk, Dalnewost. Otd., BioL-Pochv. Inst. J, 175.

GAMBARYAN, S. K. 1992. Hepatic flora of the Soviet Far East. - Bryobrothera 1: 73-78.

[GAPON, S. V.] ГАПIOH, C. В. 1992. Мохоподі6ні в eniфiтних о6ростаннах. - [Bryophytes in epiphytic overgrowths]. Укр. Бот. Журн. [Ukr. Bot. 2hurn.] $49(2): 56-59$.

[GORDEEVA, M. M., E. A. IGNATOVA \& N. G. ULANOVA] ГOPДEEBA, M. M., E. A. ИГНАТОВА, Н. Г. УЛАНОВА 1990 . Бриофлора вырубок охранной зоны Центрально-Лесното заповедника. - [Bryophytes of clear cuttings of protected surroundings of Zentraino-Lesnoi Reserve]. Hosocmu Cucm. Huзu. Pacm. [Nowosti Sist. Nizsh. Rast.] 27: 140-144.

GOS, K. 1990. The influence of the cement plants in Wojherowo (N Poland) on the moss flora of the adjacent forest. - In: Schljakov, R. N. (ed.) Abstr. 7th Meeting Centr. \& East Europ. Bryol. Working Group, Kirovsk - Apatity, 25-30 June 1990. Apatity, Acad. Sci. USSR, Kola Sci. Center, PolarAlpine Bot. Garden: 26

GRABOVIK, S. I. 1990. The influence of some ecological factors on the increment and intensity of sporophyte production in Sphagnum fuscum. - In . Schljakov, $R$. N. (ed.) Abstr. 7th Meeting Centr. \& East Europ. Bryol. Working Group, Kirowk - Apatity, 25-30 June 1990. Apatity, Acad. Sci. USSR, Kola Sci. Center, Polar-Alpine Bot. Garden: 27. 
[GRABOVIK, S. I.] ГРАБОВИК, С. И. 1991. Прирост сфагновых мхов в зависимости от экологоценотических условий на болотах Южной Карелик. - Wrowth of Sphagna in relation to ecologo-coenotical conditions on bogs of Southern Karelia]. Бриология в СССР, ее достихения и перспективы (Мат. конф., ЛЬөов, 10-12 сент. 1991) (ред. Демкив, О. Т.), ЛЬоО⿴, АН СССР. AH YCCP [In: Demkiv, O. T. (ed.) Briologia $\nu$ SSSR, ee dostizheniya i perspektivy (Proc. Conf. Lwov, 10-12 Sept. 1991). Lwov, Akad. Nauk SSSR \& Akad. Nauk Ukr. SSR]: 56-59.

GROLLE, R. 1990. Hepatics in amber - a window into the past. - In: Schljakov, R. N. (ed.) Abstr. 7th Meeting Centr. \& East Europ. Bryol Working Group, Kirowsk - Apatity, 25-30 June 1990. Aputity, Acad. Sci. USSR, Kola Sci. Center, PolarAlpine Bot. Garden: 28.

HAAB, H. 1991. Veesamblad - vaeheuuritud jaervetainsed. - [Insufficiently studied plants of lakes mosses]. Tallinna botaanikaaia uurimused IV. Botaanika ja oekoloogia: 62-70.

HEDENAES, L. 1989. Ambiystegium longicuspis Lindb. \& H. Arn., its status and taxonimic position. - Lindbergia 14: 142-146.

HEDENAES, L. 1990. Additions to the moss floras of Estonia and Latvia. - Lindbergia 16(4): 1/3-114.

HEDENAES, L. 1990. Taxonomy in relation to habitat preferances within the Calliergon - Scorpidium Drepanocladus complex. - In: Schljakov, R. N. (ed.) Abstr. 7th Meeting Centr. \& East Europ. Bryol. Working Group, Kirows - Apatity, 25-30 June 1990. Apatity. Acad. Sci. USSR, Kola Sci. Center, Polar-Alpine Bot. Garden: 28.

HERBEN, T. 1990. Dynamics of sandstone bryophytes a permanent plot study. - In. Schljakov, R. N. (ed.) Abstr. 7th Meeting Centr. \& East Europ. Bryol Working Group, Kirowk - Apatity, 25-30 June 1990. Apatity, Acad. Sci. USSR, Kola Sci. Center, Polar-Alpine Bot. Garden: 30-31.

[HOLUBETS, M. A., O. T. DEMKIV \& R. T. RIPETSКУ] ГОЛУБЕЦ, М. А., О. Т. ДЕМКИВ, Р. Т. РИПЕЦКИИ 1990. Соматическая гибридизация различно детермннированных клеток растений. [Somatic hybridization of differently determined plant cells]. Тез I Всес. План-Отч. Конф. по направлению "Геннная и клеточная инхенерия", Пучиниома-Оке, нох6рь-дехабрь 1990 М., Гос. Научн.Техн. Прогр. "Новейшие методы Guouxкенерuи"I Abstr. I All-Union Conf. 'Gene and Cell Ingeneering" ('Genna-ya $i$ Kletochnaya Inzheneria"\}, Pushchino-na-Oke, Nov-Dec. 1990. Moscow, Gos. Nauchn-Tekhn. Progr. "Noveishie metody bioinzhenerii]: 98-99.

HORTON, D. 1990. Peatland habitats in the unglaciated interior of North America. - In: Schljakov, R. N. (ed.) Abstr. 7th Meeting Centr. \& East Europ. Bryol Working Group, Kirovsk - Apatity, 25-30 June 1990. Apatity, Acad. Sci. USSR, Kola Sci. Center, Polar-Alpine Bot. Garden: 80-81.

HUNECK, S. 1990. Chemotaxonomy of the Marchantiidae. - In. Schljakov, R. N. (ed.) Abstr. 7th Meeting Centr. \& East Europ. Bryol Working Group, Kirousk - Apatity, 25-30 June 1990. Apatity, Acad. Sci. USSR, Kola Sci. Center, Polar-Alpine Bot.
Garden: 31

IGNATOV, M. S. 1990. New tecored of masses from the northwestern Altai Mountains. - Acta Bryclichenologica Asiatica $2(1-2): 17-24$.

IGYA TOV, $M$ S. 1990 . The relationship of moss flora of Altai Mts. In Schljakov, R. N. (et.) Abstr. 7th Meeting Centr. \& East Europ. Bryol Working Group, Kirousk - Apatity, 25-30 June 1990. Apatity, Acad. Sci. USSR, Kola Sci. Center, PolarAlpine Bot. Garden: 32.

IGNATOV, M. S. 1990. Upper Permian moses from the Russian Platform. - Palaeontographica, Abt. B 217(4-6): $147-189$.

[IGNATOV, M. S.] MMATOE, M. C. 1991. K 6риогеография Aтrax. - IOti the bryogeography of Altai]. Бриологія a СССР, ее достихения $\nu$

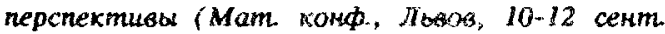
1991) (ред. Демкив, О. Т.), Л Веж, АН СССР, AH YCCP /In: Demkiv, O. T. (ed.) Briologia $v$ SSSR, ee dostizheniya i perspektivy (Proc. Conf., Lrov, 10-12 Sept. 1991). Lwov, Akad. Nauk SSSR \& Akad. Nauk Ukr. SSR J: 9l-9j.

IGNATOV, M. S. 1991. Bryokhutulinia jurassica, gen. et spec. nova, a remarkable fossil moss from Mongolia. - J. Hattori Bot. Lab. 71: 377-388.

IGNATOV, M. S. 1992. On the cccurence of Barbula inaequalifolia Tayl. (Pottiaceae, Musci) in Altai Mountains. - Yxp. Bom. Журн. [Ukr. Bot. Zhurn] 49 (1): 95-97.

IGNATOV, M. S. 1992. The relationships of moss flora of Altai Mts. - Bryobrothera 1: 63-72.

[IGNATOV, M. S. \& o. M. AFONINA (eds.)] ИГНАТОВ, М. С., О. М. АФОНИНА (ред.) 1992. Cписок мхов территорин быnmero CCCP. [Check-list of moses of the former USSR]. Arctoa I (1-2): 1-85

[IGNATOV, M. S. \& E. A. IGNATOVA] ИITATOB, M. C., Е. А. ИГНАТОВА 1990. Матерналы $x$ познанию брнофлоры Московской области. [Contribution to the bryoflors of Moscow Province]. Фropucmurecкue исстеdoanнus a Mосковской

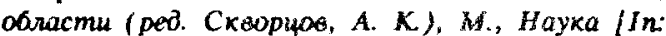
Skwortsov, A. K. (ed.) Floristicheckie issledowaniya $\checkmark$ Moskorkoy oblasti. Moscow, Nauka]: 121-179.

[IGNATOV, M. S. \& E. A. IGNATOVA] MIHATOB, M. C., E. A. MГНАТОВА 1991. Брнофлора Прнокско-Террасного госдарственного биосферного заповедника. - [Bryoflora of Prioksko-Terrasnyj State Biosphaeric Reservel. Mзучекue экосистем Приокско-Теросного госкарстьенного биосферного запоееонка (Керхенцей, A. C. (ред.), Пушщно-на-Оке, АН СССР, Пушинский Научн. Иентр IIn: Kerzhenzev, A. S. (ed.) Izuchenie ekosistem Prioksko-Terrasnogo gosudarstvennogo biosfernogo zapowednika Pushchino na-Oke, Akad. Nauk SSSR, Pushch Nauchn. Zentr]: 6-20.

[IGNATOV, M. S., E. A. IGNATOVA, D. A. PETELIN \& B. F. KHASANOV] ИГHATOB, M. C., E. A ИГНАТОВА, Д. А. ПЕТЕЛИН, Б. Ф. ХАСАНОВ 1990. Материалы к брнофлоре Буреннского заповедника (Хабаровский край)... [Contributions to the bryoflora of Bureya Reserve (Khabarovsk Territory)]. Бюли Моск. O-єа Исn. Прир. Oma. 
Bwon Bull. Mosk. Obshch Isp. Prir. Otd. Bioly 95(6): $86-96$

IGNATOV, M. S. M. KuRBATOVA 1990 Deepwater bryophytes: revew with new reconds from the USSK. Hikobis $10: 1-16$.

[IGNATOV, M. S. O. M. MASLOVSKY] hIHATIB М. С., О. М. МАСЛОВСКИЙ 1990. К брноqПор окрестностей Кунгура (Пермская область). - [1h the bryoflor of Kungur surroundings (Perm Province)]. Bron. Гrash. Bom Cade (Bull Glum Bot. Sada/ 158: 23-28.

IGNATOV, M. S. \& B. C. TAN 1991. Orthodonopsis, a new genus of Bryaceae (Musci) from southern Siberia, USSR. - J. Hattori Bot. Lab. 71: $105-173$

[IGNATOVA, E. A. M. S. IGNATOV] ИГHATOBA, E. А., М. С. MTHAтOB 1993. Мхи Бамикичи предварителыный список видов и фито reотрафические заметки. - IMoses of Bashkiria: preliminary list of specics and phyiogeographical

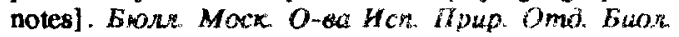
[Bull. Mosk Obshch. Isp. Prir. Otd Biol./ 981]: 103- 111 .

[IGNATOVA, E. A., J. VANA \& I. M. VOROBYOVA] ИГНАТОВА, E. A., A. ВАНA, D. $M$. ВОРОББЕВА 1990. Брнофлора Тебердинскот заповедника. - [Bryoflora of Teberda Reserve]. Tpydu TeGepdumckozo заnocedнuкa /Trudy Tebeniinskogo Zapovednika] 12: 1-40.

INGERPUU, N. \& H. KRAIL 1990. The hepatics of Estonia. - In-Schljakov, R. N. (ed.) Abstr. 7th Meeting Centr. \& East Europ. Bryol. Working Group, Kirowk - Apatity, 25-30 June 1990. Apatity, Acad. Sci USSR, Kola Sci Center, Polar-Alpine Bot. Garden: 33-34.

INGERPUU, N. \& H. KRALL 1991. Hepatics of Estonia - [Eesu koeder- ja inaksasambiad]. Scripta botanica 6. 34-53.

INGERPUU, N. H. KRAII, A. KALDA, L KANNUKENE \& M. LEIS 1992. New species in the Es tonian bryoflora. - Folia Cryptogamica Estonica 29: $38-41$.

KALDA, A. 1990. Nikolai Malia ja Eesti. - [Nikolai Malta and Estonia]. Eesti Lackius (12): 816

KALDA, A., L. KANNUKENE \& M LEIS 1992. Rart mosses in Estonta and their protection. - Biol Conservation $59(2 \cdots 3): 201-203$.

KANNUKENE, L. 1990. Muhu Lehtsmblad. - [Mosses of muhumaa). Muhumbia Loodusest. Tailinn - Muhu. Muhukulanoukogiu, Muhu Selts d Eesti Botanikeaat: $20-2$ ]

KANNUKENE, L. 1990. Mosses. Flora and regetation of Saaremu island. Tartu: 24-28.

KANNUKENE, L. S I.IIV, E. SANDER \& A. TARAND 1991. Raskemetaliid Eesti sammaldes. - [Heavy metals in mosses in Estonial Tallinna botaanikaaia uurimused IV. Botaanika ia cekoloogia 148161.

KAPДAIU, A. P. [KARDASH, A. R.] Opranizdzis мікрофібрнл целюлозн в клітинних стінках на ранніх стадіях розвитху гамeroxplтy моху Funaria hygrometrica Hedw. - [Cellulose microfibrills in cell walls on early stages of development of ganetophyte: of moss Funaria hygrometrica Hedw.]. Актуальнi

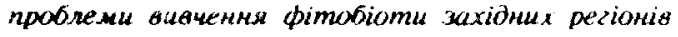

Украіни (Mam Kond, Iosis, 2-5 коімня 1990)

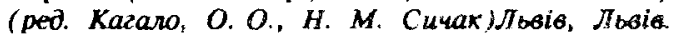
Bid. In-my Боm. AH YPCP, Лbsi6. Дер* Ун-m IIn. Kagalo, $O . O$ of N. M. Sychak (ed.). Aktualni probiemy vywhennya fitobioty zakhidnykh regioniv l'krauny (Proc. Conf., Lviv, 2-5 Apr. 1990) Lviv, i.vis Vid. inst. Bot. Akad. Nauk Ukr. RSR \& Lviv. Derzh Univ. !: 51-53.

KARUASH, O. R. 1990. The arrangemeni of cellulose microfibrils in the process of the protonema development. - In: Schljakov, R. N. (ed.) Abstr. 7th Meeting Centr. \& East Europ. Bryol. Working Group, Kirowst - Apatity, 25-30 June 1990. Apatity, Acad. Sci. USSR, Kola Sci Center, Polar-Alpine Bot. Gaden: 35 .

[KARDASH, A. R.] KAPLAIU, A. F. 1991. Рост н бноэлехтрическая поляризация клеток протонемы мхон. - [Growth of bioelectrical polarization of protonema cells of mosses]. Бpuorozus a CCCP, ee достихения и перспективы (Мат. конф., Jына, 10-12 сент 1991) (ред. Демкия, О. Т.), Льаб, AH CCCP, AH YCCP IIn. Demkiv, O.T. (ed.) Briologia v SSSR, ee dostizheniya $i$ perspektivy (Proc. Conf., Lwov, 10-12 Sept. 1991). Lwov, Akad. Nauk SSSR \& Akad. Nauk Ukr. SSR]: 99-102.

[KARDASH, A. R. \& L. O. DEMKIV] KAP ДAIII, A. P., Л. О. ДЕМКИВ 1991. Вилив СвнНцю на ріст та poзвиток гаметофiтy Funaria hygrometrica Hedw. [Effect of lead on the growth and development of gametophyte Funaria hygrometrica]. Yxp. Bom. Журн. [Ukr. Bot. Zhurn.] 48(5): 3I-33.

[KARDASH, O. R., N. A. KIT, O. T, DEMKIV] КАРДАШІ, О. Р., Н. А. КНТ, О. Т. ДЕМКІВ 1992. Значення ризоідів для пормональноі регуляиіi розвитку гаметофіта мохів. - [Rhizoids in the hormonal regulation of the moss gametophyte development]. Y'кp. Боm. Журн. [Uk. Bot. Zhurn] $49(5): 99-103$.

[KAZANOVSKY, S. G.] КАЗАНОВСКИЙ, С. Г. 1991. Новинки бриофлоры Сибири. - [New records for the bryollora of Siberia]. Бom Журн [Bot. Zhurn] 76(3): $458-460$.

[KAZANOVSKY, S. G.] КАЗАНОВСКИЙ, С. I'. 1991. K бриофлоре Байкальского заповедника. - [On the bryoflora of Baikal Reserve]. Бpuonozus $\theta$ СССР, ее достихения и перспектияв (Mam. конф., ЛьяОв, 10-12 сент. 1991) (ред. Демкив, O. T.), IboOs, AH CСCP, AH YCCP /In: Demkiv, O. T. (ed.) Briologia y SSSR, ee dostizheniya i perspektivy (Pro. Cont., Lwov, 10-12 Sept. 1991). Lwov, Akad. Nauk SSSR \& Akad. Nauk Ukr. SSRl: $94-98$.

[KHORKAVTSIV. ҮA. D.] ХOРКАВНИВ, Я. Д. 1990. Регуляция взанмовлихний в мзолированных клеточных системах мхое. - [Regulation of interinfluences in isolated cell systems of mosses). Tez. Докл 2 Свезda Всес. O-ва физиалогов растений, 4. IJ, Минск, 24-29 сент. 1990 Москва, АH CCCP, Bcec. O-во Фuзиor Pacm. /Abstr. 2 Congr. of All-Urion Soc. Plant Physiol, Pt. II, Minsk, 2429 Sept. 1990 Moscow, Akad. Nauk SSSR, Vses. Obshch Fiziol Rast. I: 95.

[KHORKAVTSIV, YA. D.] XOPKABЦИВ, Я. Д. 1991. Методические подходы $x$ изученик манмодейстния хлетох в процессе нх 
pervepannи. - [The metodic approaches of studies of seliviar interactions in procese of regeneration].

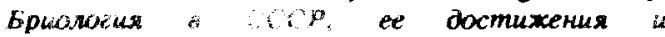

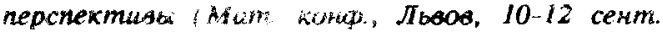

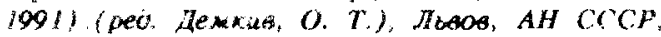
AH YCCP In Lemkiv, O "T. ied.) Bridiokia " SSSR, ee dostizheniya i perspektivy (Pro tont. Lyov, 10-12 Sept. 1991). L.ov, Akad. Nank SSSR \& Akad. Naut Ukr. SSRI: 192-195

[KHORKAVTSIV, YA. D. K K. O. LLYCHNA] ХОРКАВЦИВ, Я. Д., Х. О. УЛІЬІЧМА 1990. Сравнительное исследование Bryum violaceum Crundw. et Nyh. B B. klinggraeffi Schimp. (Musci) c заnада УССР. - [Comparative study of Bryum violaceum Crundw. et Nyh. and B. klingraeffil Schimp. (Musci) on West of Ukrainian SSRl. Yxp. Fom. Журн. /Ukr. Bot. Zhurn./ 47(3): 32-36.

[KHORKAVTSIV, YA. D. \& O. T. DEMKIV] ХОРКАВЦИВ, Я. Д., О. Т. ДЕМККВ 1991 Морфоломические основы адаптацим мхов. [Morphological basis for bryophyte adaptation]. Lumosozus [Citologia] $33(5): 141$.

[KTT, N. A. \& R. T. RIPETSKY] KKT, H. A., P. T. РИПЕЦКИ 1991. На6люденкя над развитиен первичной и ретенеративной протонемы мха Pottia intermedia (Turn.) Fuernr. - [Observations on development of primary and regenerated protonema of moss Pottia intermedia (Turn.) Fuemr.l. Бриология - СССР, еe достихения и перспектияы (Mam. конф., Льөов, 10-12 сент. 1991) (ред. Демкив, О. Т.), ЛЬвО6, АН СССР, AH YCCP IIn: Demkiv, O. $T$. (ed.) Briologia $v$ SSSR, ee dostizheniya $i$ perspektivy (Proc. Conf., Lwov, 10-12 Sept. 1991). Lwv, Akad. Nauk SSSR Akad. Nauk Ukr. SSR]: 103-106.

[KONSTANTINOVA, N. A.] KOHCTAHTHHOBA, Н. А. 1990. Новме находки редких видов печеночников из Мурманской области. - [New records of rare hepatics [rom Murmansk Province]. Бom. Журн. [Bot. Zhurn.] 75(9): 1306-1308.

[KONSTANTINOVA, N. A.] KOHCTAHTИНOBA, H. A. $1990 . \mathrm{K}$ флоре печеночнихов севера Архангельской области (по сборам Ф. И. Pynpexra, 1841). - [On the hepatic flora of the North of Arthangelsk Province (by collections of F. I. Ruprechi, 1841)!. Ботанические икслебования за Полярным кругом (ред. Лукияноеа, Л. М.), Кировск, Кол Ото. ВБО; АН СССР, ПолярноArbn Bom. Cod [In. Lakyanowa, L M. (ed.) Botanicheskie issledomaniyo za Polyarnym krugom. Kirarsk, Kol Otd. Vses. Bot Obshch \& Polyarno Alp. Bot. Sad ]: $92-97$.

KONSTANTINOVA, N. A. 1990 De Lebermoos-Flora der Lovosee-Berge (Lovozerskic Gory). - Feddes Repert. $101(5-6): 311-31.3$.

KONSTANTINOVA, N. 1992. Protection of bryophytes in the Murmansk Region (Russiaj. . Biol. Conservation $59(2-3): 191-195$.

IKONSTANTINOVA, N A. O. A. BELKINA \& A. YU LIKHACHEV] KOHCTAHTHHOBA, H. A.O A БEJKИНА, А. Ю. ЛИХАЧЕВ 1991. Редки мохо0бразғіле и их охрана в Мурманской 06лtcrs. - [Rare bryophytes of Muranansk Province and its conservation]. Бpuoлozus

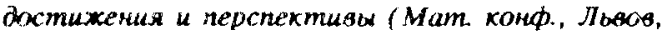

10-12 сенm 1991, (put. Денкиe, O. T.), Ibo0s,

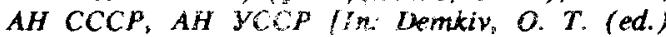
Briologia v SSSF, ee dostizheniya i perspektivy (Proce Conf, Lwov, 10-12 Sept. 1991). Lwov, Akad. Nouk SSSR \& Akod. Nauk Uth. SSR 1: 107-112.

KESSHATROVA, N. A. \& A. YU, LIKHACHEV toro 3ryophytes of the Olenil Island (the Kandalakshe bay of the White Seris. - In Schljakov, $R$. N. (ed.) Abstr. 7th Meeting Centr. \& East Europ. Bryol Working Group, Kironk "Apatity, 25-30 Iune 1990 . Aputity, Acad Sci. USSR, Kola Sci. Center, Folar-Alpine Bot Gorden: 36.

[KONSTANTINOVA, N. A. A. D. POTEMKIN \& R. N SCHIJAKOYI KOHCTAUTHHOBA, H. A., A. I. ПОТЕМКИН, Р. Н. IUTЯKOE 1992. Список печеночников и антоцеротовых террнтория 6ывwen CCCP. - [Check-list of the Hepaticae and Anthocerotal of the formet USSR\}. Arctoa 1(1-2): $87-127$

KONYA, E. 1990. Examinations of the moss cover in different plant communities. - In Schljakov, $R$. $N$. (ed.) Abstr. 7th Meeting Centr. \& East Europ. Bryol. Working Group, Kirowk - Apatity, 25-30 June 1990. Apatity, Acad. Sci USSR, Kola Sci. Center, Polar-Alpine Bot. Guden: 37-38.

KOPONEN, T. \& O. AFONINA 1992. Miscellaneous notes on Mniaceae (Bryophyth). XV. Genus Rhizomnium in the Russia east of Ural Mts. - Bryobrothera 1: $245-250$

[KORDYUM, E. L., E. M. NEDUKHA \& K. I. CHABAN] KOPДЮM, Е. JI., Е. М. НЕДУХА, Х. И. ЧАБАН 1991. Мхи - модельные объекты космичесхой биологни. - [Mosses as model objects of space biology]. Вpuonozisa a CCCP, ee

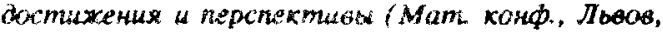
10-12 сенm. 100i) (pet. Немкия, O. T.), Iboos, AH CCCP, AH YCCP (In Demkiv, O. T. (ed.) Briologia $v$ SSSR, ze dostizheniya $i$ perspektivy (Proc. Conf., Lwov, 10-12 Sept. 1991). Lvov, Akad. Nank SSSR \& Akad. Nauk Ukr. SSR]: 112-116.

[KOSHKAREVA, I. G.] KOWKAPEBA, Л. Г. 1990. Эколого-георафические условн роста и формирования фнтонассы н ельниках из ели Шренка. - [Ecologo geographical conditions of growth and development of fitomass in spruce forests of Picea schrenkiana]. Проблемы zеoэкологин $u$ природопользования сорных территорий

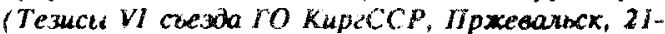
23 мая 1990) Фрунзе, Нлим (Probiemy geckologit i priridopolzonaniya gornykh territorif (Abstr. VI Congr. of Geogr. Soc. of Kirg. SSR, Przhevalsk, 21-23 May 1990). Frunze, Ilim]: 143144.

[KOSHKAREYA, L. G.] KOUKAPEBA, Л. Г. 1990.0 средфобразующей роли моховой хомюонекты в ельниках из ели Шіренка. -. [Influence of mosses on environments in forests of Picea schrenkiana] Нроблема геожкиоги и природопользования горных территорий (Тезисы VI съезда ГО КирсССР, Пржевальск, 21-23 мая 1990) Фрунзе, Hлим Problemy geockologii $i$ priridopolzowaniya gornykh territorif (Abstr. VI Congr. of Geogr. Soc. of Kirg. SSR, Przhewalsk, 21-23 May 1990). Frunze, Ilim ]: $144-145$. 
KOSHKAREVA, L. G, 1990. Ecological-phy toococolugical variability Abietinella abietins in spruce forests of Central and torthert thes Shan. - In: Schilakon, $\boldsymbol{R}$. N. (ad.) Abitr. Tht Meeng Centr. \& East Euroy. Brwl. Working Gruap, Kirovs . Apatip. 25 30

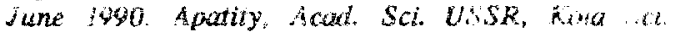
Center, Polom Aipize Bot. Garden: $38-39$

[KOSHKAREVA, L. G.] KOHLAPEBA, $\mathrm{I}, 7$, Mохообразнwе \& ельниках Cеверног

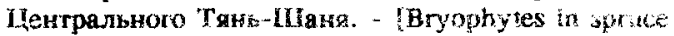
forests of Northera and Central Tian-Shanl

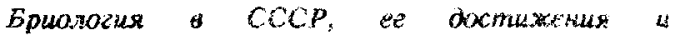

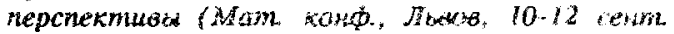

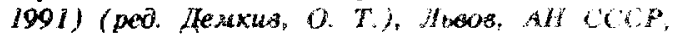
AH YCCP IIn: Demkib, O. T. (ed.) Briologk v SSSR, ee dostizheniya i perspektivy lproc Cotif. LWov, 10-12 Sept. 1991). L.Wov, Akoul. Nauk SSSR \& Akad. Nawk Ukr. SSRl: 117-i20.

[KOSHKAREVA, 4, G. I KOIIKAPERA, H. I. ¿991

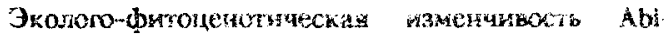
etinella abletira a enbruks Cerepsor

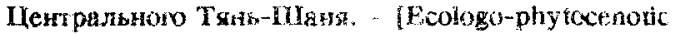
variability of Abietinelia sthetina in spruce forests of Northeem and Cental Tun-Shan!. Cmausowapkwe

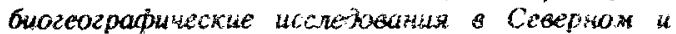

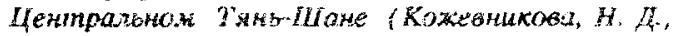
ped.) Buskex, Hriss itn Rozhevitikova, N. D. (ed.) Stazionarnye biogeographicheskic issiedowaniya $y$ Severnom i Zentralnom Tian-Shane. Bishkek, Ilim I: 105-11l.

[KUCHERYAYY, Y. A., 5. YA. KONDRATYUK, V. M. YIRCHENKO A $Y$. A. KRAMARETS] KYYEРЯВЫИ, В. А., С. Х. КОНLРАТЕК, В. М. ВИРЧЕНКО, В. А. КРАМАРЕL 1990. Лихено- и

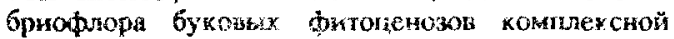

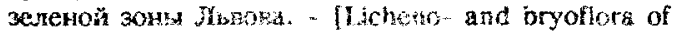
beech phytowcenosis of the complex-green-zone of

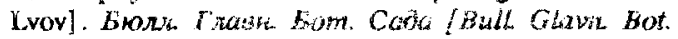
Sada) 157: $45-50$.

[KULIK, T. G.] KYJUL, T. Г. 1990. Marepma.tw no cemencrbax Brachytheciaceae (poдw Isothecium, Myuroclada, Scleropotium), Entodontaceae (род Entodon), Hypraceac (pon Pleurozium) E брнологичесхон repbapta. - ISpecinens of families Brachytheciacege (genera isothecium, Myuroclada, Scleropodium), Entodonfacene (genus Entodon), Hypnaceae (genus Pleurozium) in bryological

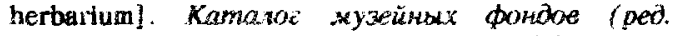

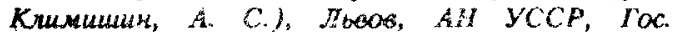

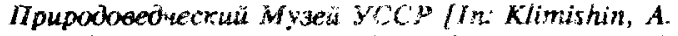
S. (ed.) Kataiog muzeinykh fondov. Lwov. Akad. Nauk Ukr. SSR, Oos. Prirodoweicheskij Musei]: 62.5.

[KULIK, T. G. K. O. ULYCINA] KYJUK, T. I, K.

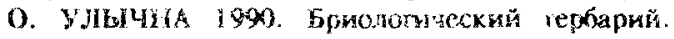
Cemeñctio Neckeracede. [Bryological Herbarium.

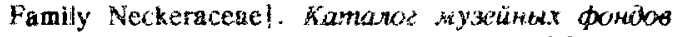

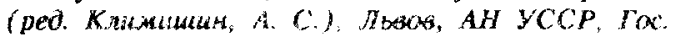

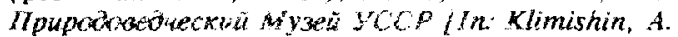
S. (ad.) Kutalog miseinykh fondov. LWov, had. Nauk Ikr. SSR, Gas. Prirodoved cheskij Museil: 26 44.

[KUZMINA, E. YU.] KУЗWMLUA. E. H. 1990. Участие мхов $\mathrm{s}$ титвчных растителыных сообщестьах окрестностей ПІекульнейскоио изера (Kopaxcko: нaropse). -. Participation of mosses in hain plant communities of surroundings of Pekulneiskoye Lake (Xoryakskoye High-Land)]. Tpydo 3 мол конф. ботаников Мениндрада, 4. Ленинера木, anp. 1990. M., АН СССР, Бот Нн-m ,Len. BHHИTH 14. XI. 1990, N 570-B90. ITrudy 3 conf. tot Leningrada, Pt. I Leningrad, Apr. 1990. ieningrad, Akad. Nauk SSSR, Bot. Inst. MSC. Reserved in VINITI 14. XI. 1990, N 570-B90.]: 217. 229.

[KUZMINA, E. YU.] КУЗЬMHНA, E. Ю. 1992. Материалы $\mathrm{x}$ флоре листостебельных мхов Kopsixckoro Haropbs. - [Contributions to the moss flora of Koryakskoye Figh-Land]. Hobocmu Cucm. Husu. Pacm. [Nowosti Sist. Nizsh Rast.] 28: 145148.

[LIKHACHEV, A. YU] ЛИXАYEB, A. Допонение $*$ брниqлоре Кандалакшских и Колвицких кор (Мурмансках область) Ботанические исследования за Полярным хругон (реd. ІІукьянова, Л. М.), Кировск, Кал Omd. BBO; AH CССP, Полspro-Arbn Bom CaÓ IIn: Lukyanowa, L. M. (ed.) Botanicheskie issiledowaniya th Polyarnym krugom Kirows, Kol Otd. Vses. Bot. Obshch \& Polyarno-Alp. Bot. Sad]: 8691.

[LOBACHEVSKA, O. V.] ЛOБАЧЕВCbKA, O. B. 1990. Поліплоідія соматичних клітин моху Tortula muralis Hedw. - [Polyploidy of somatic cells of Tortula muralis Hedw.]. Укp. Bom. Журн [Ukr. Bot. Zhurn.] 47(4): 86-89.

LOBACHEVSKA, O. V. 1990. Variability of the content and species structure of leafy mosses. - In: Schljakov, R. N. (ed.) Abstr. 7th Meeting Centr. \& East Europ. Bryol Working Group, Kirowsk - Apatity, 25-30 June 1990. Apatity, Acad. Sci. USSR, Kola Sci. Center, Polar-Alpine Bot. Garden. 40.

[I.OBACHEVSKA, O. V.] NOБAYERCKAЯ, O. B. 1991. Цитохимическое исследование гетерохроматина Tortula muralis Hedw. - [Cytochemical researches of heterochromatine of Tortula muralis Hedw.]. Брuологus 6 CCCP, еe достихения $u$ nepcnesmuä (Mam. конф., Jlбео6, 10-12 сент. 1991) (ред. Демкия, О. T.), ЛЬе\%, АН СССР, AH YCCP II $\mathrm{H}$ : Demkiv, O. $T$. (ed.) Briologia $v$ SSSR, ee dostizheniya i perspektivy (Proc. Conf, Lvov, 10-12 Sept. 1991). Lwov, Akad. Nauk SSSR \& Akad. Nauk Ukr. SSRJ: 121-124.

LLOBACHEVSKA, O. V.] JOBA HEBCbKA, O. B. 1991. Активність карбоангідрази мохоподібннх. [The activity of carboangydrase of mosses]. Актуальні проблеми виячення фітобіоти західних реzіонія Украіни (Мат. Конф., Льsis, 2.5 квімка 1990) (реd. Каzало, О. О., Н. М.

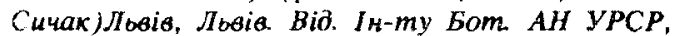
Ibsia. Дepж. Yu-m /In: Kagalo, O. O\& N. M. Sychak (ed.). Aktualni problemy vyvchennya fitobioty zakhidnykh regioniv Ukrainy (Proc. Conf., Lviv, 2-5 Apr. 1990) Lviv, Lviv. Vid. inst. Bot. Akad. Nauk Ukr. RSR \& Lviv. Derzh. Univ. ]: 68-70.

[LOBACHEVSKA, $O$. V. \& $0 . \quad T$. DEMKIY] IОБА ЧЕВСЬKА, O. В., O. T. ДЕМКIB 1990. Міндиніст вмісту ДНК в ядрах листяних мохів. (Variability in the DNA content in nuclei of leaf mosses] Ykp. Bom. Kypt. [Ukr. Bot. Zhurn] 
$472: 17-24$

[IOBACHEVSKA G V., I. O. DEMKIV \& O. R. KARDASH! MOGAYEBLCKA, O. B., II. 0 .

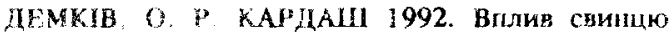
in pice i posвwток мохів. - [The effect of irad on growth and development of nusses!. Ko. Bom. Журн /Ukr. Bot. Zhurn.J $49(2)$ : 50-5.5.

[LOBACHEVSKA, O. V., O. T. DEMKIV \& N. A. KIT] JОБАЧЕВСКАЯ, О. В., О. Т. ДЕМКИВ, Н. А. КИТ 1991. Внутривидовые различия у мхов в "стойчивости $\mathrm{k}$ токсическому действию тыжелых veraллов. - [Infraspecific variability of mosses in tolerance to toxicant action of heavy metals]. Ilumonozus /Cytologia] 33(5):112-113

MAKSIMOV, A. I. 1990. On geography of Sphagnum subfulvum in the USSR European Part - In: Schljakov, R. N. (ed.) Abstr. 7th Meeting Centr. \& East Fiurop. Bryol. Working Group, Kirovsk Apatity, 25-30 June 1990. Apatity. Acad. Sci. USSR, Kola Sit. Center, Polar.Alpine Bot. Garden: 41.

[MALINOVSKY, К. А.] МАЛИНОВСКИЙ, К. А. 1991. Идеи А. С. Лазаренко в ботанической геогратик цектковых растений. - [Ideas of A. S. Lazarenko in phytogeagraphy of vascular plants]. Бриологuя $\theta$ СССР, ее достижения и перспективы ( $\mathrm{Mam}$ конф., Льаов, 10-12 сент. 1991) (ред. Демкив, O. T.), J $O$. T. (ed.) Briologia y SSSR, ee dostizheniya i perspektivy (Proc. Conf., Lvov, 10-12 Sept. 1991). Lvov, Akad. Nauk SSSR \& Akad. Nauk Ukr. SSRl: $125-131$.

MALYSHEVA, T, V. 1990. On forest bryology, lichenobryology. - In. Schljakov, R. N. (ed.) Abstr. 7th Meeting Centr. \& East Europ. Bryol. Working Group, Kirowk - Apatity, 25-30 June 1990. Apatity, Acad. Sci. USSR, Kola Sci. Center, PolarAlpine Bot. Garden. 42.

[MALYSHEVA, T. V.] MAJHIUEBA, T B. 1991. Нєкоторые вопросы лесной лихено-брнологи. [Some aspects of forest licheno-bryology]. Бриология 8 СССР, ее достижения и nерспективы (Mam. конф., ЛЬњ08, 10-12 сект. 1991) (ред. Демкив, О. Т.), Льеов, АН СССР, AH YCCP IIn Demkiv, O. T. (ed.) Briologia $v$ SSSR, ee dostizneniya i perspektivy (Proc. Conf., L.vov, 10-12 Sept. 199!). Lvov, Akad. Nauk SSSR \& Akad. Nauk Ukr. SSR 1: 132-136.

[MALYShEVA, T. V.] MAJbILIEBA, Т. В. 1992. Роль мохообразных и лишайников в жизни леса. Ч. І, - [Role of bryophytes and lichens in forest life. Pt. I]. M., PAH, Hн-m Jlecoederha [Moscow. Ross. Akad. Nauk, Inst. lesovedenival, 222.

[MALYSHEVA, 'T. V.] MAJblLIEBA, T. B. 1992. Porh мохообразиых и лишайников в жизни леса. Ч. И. - [Role of bryophytes and lichens in forest life. Pt. II]. M., РAH, Ин-m Jеcoвеdeния /Moscow, Ross. Akad. Nauk, Inst. Lesovedeniyal, 169.

[MAMATKULOV, U. K.] MAMATKУЛОВ, У. К. 1990. Флора мохообразных Таджикской ССР. Т. 1 . Cфагновbе - Гриммневble. - BBryophyte flora of Tadjikskaya SSR. Vol. 1. Sphagnaceac - Grimmiaceae]. Дунанбе, Дониа [Dushante, Donish], 234.

MAMATKUION, U. K. 1990. Genus Tortula Hedw. in
USSR. - In. Schliakov, R. N (ed.) Abstr. 7th Meeting Centr. \& East Europ. Bryol. Working Group, Kirowsk - Apatity, 28-30 June 1990. Apatity, Acad. Sci. USSR, Kola Sci. Center, PolarAlpine Bot. Garden: 4344.

MAMATKULOV, U. K. 1990. Genus Tortuia Hedw. in USSR. - In. Schijakov, $R$. $N$ (ed.) Abstr. 7th Meeting Centr. \& East Europ. BryoL Working Group, Kirowsk - Apatity, 25-30 June 1990. Apatity, dcad. Sci. USSR, Kola Sci. Center, PolarAlpine Bot. Garden: $4-44$.

MAMATKULOV, U. K. 1990. Oekologische und phytogeographische Besonderteiten Ger Moosfiora Mittelasiens. - Feddes Repert. $101(5-6): 315-317$.

[MAMATKULOV, U. K.] MAMATKYJIOB, У. K. 1991. Ботанико-географическая кондепиия у трудах $\mathrm{A}$. C. Лазаренко. - [Botanico-geographical conception in works of A. S. Iazarenko]. Spuonozus a CCCP, ее достихения а перспехтива (Мат конф., J beos, 10-12 сент. 1991) (реб. Демкив, О. Т.), Ilbaos, AH CCCP, AH YCCP IIn: Demkiv, O. T. (ed.) Briologia v SSSR, ee dostizheniya $i$ perspektivy (Proc. Conf., LWOV, lo-12 Sept. 1991). LWOV, Akad. Nauk SSSR \& Akad. Nouk Ukr. SSRI; 137142.

MAMCHUR, Z. I. 1990. Epiphytic mosses of the associations from the Lvov Region. - Int Schljakov, R. N. (ed.) Abstr. 7th Meeting Centr. \& East Europ. Bryol. Working Group, Kirowk - Apatity, 25-30 June 1990. Apatity, Acad. Scl. USSR, Kola Sci. Center, Polar-Alpine Bot. Garden: 44-45.

[MAMCHUR, Z. I.] MAMЧYP, 3. I. 1991 Стан внвчення епіф)ітни мохоподібиих. иа Јьвівщині. [The state of investigations of epiphyoic bryophytes in Lviv Provincel Akmyальні проблеми вивчення фimoбiomu західних ресіонів Украіни (Маm. Конф., Jbais, 2-5 квimits 1990) (ped. Kazano,

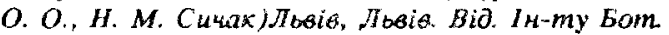
AH УРСP, Лbais. Держ. У,-m lIn Kagalo, $O . O$ \& N. M. Sychak (ed.). Aktualni problemy vyuchennya firobioty zakhidnykh regioniv Ukrainy (Proc. Conf., Lviv, 2-5 Apr 1990) Lviv, Lviv. Vid. Inst. Bot. Akad. Nauk Ukr. RSR \& Lviv. Derzh. Univ.]: 73-75.

[MAMCHUR, Z. I. \& O. T. DEMKIV] MAMYYP, 3. I., O. T. ДЕМКИВ 1991. Анализ эпифитных моховых обрастаний парков торода Львона. [Analysis of epyphytic bryophytes in parks of Lvov Cityl. Бриолосия в CCCP, еe достижения и

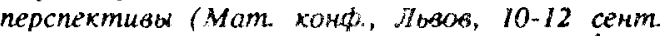

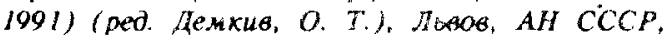
AH YCCP IIn: Demkiv, O. T. (ed,) Briologia $y$ SSSR, ee dostizheniya i perspektivy (Proc. Conf., Lrov, 10-12 Sept. 1991). L.bov, Akad. Nauk SSSR \& Akad. Nauk Ukr. SSR I: 143-146.

[MANAKYAN, V. A.] MAHAKGH, B. A. 1989. Листостеб́ельныс мхи Юго-Восточной Армении. [Mosses of South-Eastern Armenia]. Ереван, Нзо6. AH Ap.mCCP /Erevan, Akad. Nauk Arm. SSR/, 313.

MANAKYAN, V. A. 1990 . Mosses of Armenian forests. Feddes Repert. 101 (5-6): 305-309.

MANAKYAN, V. A. 1990. Review of Hepaticae of Armenian SSR. - In: Schljakov, R. N. (ed.) Abstr. 7th Meeting Centr. \& East Europ. Bryol. Working 
Alpine Bot. Garden: 45-46.

[MASLOVSKY, O. M? MACJOBCКИИ, О. М. 1990. Закономерности тандшафтного распределения видов мохохоразных в бриофлоре Белорусского Поозерьх. - Труды 3 мол конф. ботаников Ленцндрада, 4. I. Ленинграd, апр. 1990. JI. АН СССР, Бот Нн-m. Деп. ВННИТН 14. ХI. 1990, No 5700-B90/Trudy 3 conf. bot. Leningrada, Pt. $I$. Leningrad, Apr. 1990. Leningrad, Akad. Nauk SSSR, Bot. Inst. MSC Reserved VINITI 14. XI. 1990, No 5700-B90): 230-234.

[MASLOVSKY, О. М.] МАСЛОВСКИИ, О. М. 1990. Прннципы сравнительного анализа бриофлор. [Principles of comparative analyses of bryofloras] Ботаника. Нсcredoaaнuя \{Минск\} [Botanika. Issledowaniya (Minsk)/ 30: 156-160.

MASLOVSKY, O. M. 1990. Principles of analyses of landecape of Bryofiora. - In: Schljakov, R. N. (ed.) Abstr. 7th Meeting Centr. \& East Europ. Bryol. Working Group, Kinousk - Apatity, 25-30 June 1990. Apatity, Acad. Sci. USSR, Kola Sci. Center, Polar-Alpine Bot. Garden: 46-47.

[MASLOVSKY, О. М.] MACJOBCКИИ, О. М. 1991. Анализ струхтуры бриофлоротопологических хомплексов брнофлоры Белорусского Полесья. [Analysis of structure of bryoflorotopological complexes in bryoflora of Belorussian Polessye]. Бриология в СССР, ее достихения $и$ перспектияы (Мам конф., Льөов, 10-12 сент. 1991) (ред. Демкия, О. Т.), ЛЬеов, АН СССР, AH YCCP IIn: Demkiv, O. $T$. (ed.) Briologia $v$ SSSR, ee dostizheniya i perspektivy (Proc. Conf., LWov, 10-12 Sept. 1991). Lwov, Akad. Nauk SSSR \& Akad. Nauk Ukr. SSR]: 147-150.

[MATASOV, V. I.] MATACOB, B. Н. 1991. Образование эмбриотеки и гаметофитоспорофитные отноуения у лиственных мхов. [Development of embryotheca and gametophytesporophyte relationships in mosses]. Брuorozus 8 СССР, еe достихения и перспективы (Mam. конф., Льво, 10-12 сент. 1991) (ред. Демкив, O. T.), Jboos, AH CCCP, AH YCCP (In: Demkiv, O. T. (ed.) Briologia y $S S S R$, ee dostizheniya $i$ perspektivy (Proc. Conf, Lwov, 10-12 Sept. 1991). Lwov, Akad. Nauk SSSR \& Akad. Nauk Ukr. SSRJ: $151-154$

MEINUNGER, L. 1990. The genus Racomitrium in GDR. - In. Schljakov, R. N. (ed.) Abstr. 7th Meeting Centr. \& East Europ. Bryol. Working Group, Kirowsk - Apatity, 25-30 June 1990. Apatity, Acad. Sci USSR, Kola Sci. Center, Polar-Alpine Bot. Garden: 47.

MELOSIK, I. \& T. LEHMANN 1990. Esterase as a taxonomical character of Sphagnum centrale C Jens. in relation to $S$. magelianicum $B$ rid. and $S$. palustre $L$. - In. Schljakov, R. N. (ed.) Abstr. 7th Meeting Centr. \& East Europ. Bryol Working Group, Kirovsk - Apatity, 25-30 June 1990. Apatity, Acad. Sci. USSR, Kola Sci. Center, Polar-Alpine Bot. Garden: 48.

[MORDVINOV, А. N.] МОРДВИНОВ, А. Н. 1991. К бриофлоре центральной части Приволжской возвышенностн. - [On bryoflora of Central Part of Cis-Volga Upland]. Бpuonozus a CCCP, ee достихения и перспективы (Мат. конф., Л6608, 10-12 сент. 1991) (ред. Демкие, О. Т.), Льсов, AH CCCP, AH YCCP [In. Demkiv, O. T. (ed.) Briologia v SSSR, ee dostizheniya $i$ perspektivy (Proc Conf., Lwov, 10-12 Sept. 1991). Lwov, Akad. Nauk SSSR \& Akad. Nauk Ukr. SSR]: 155-159.

[MORLVINOV, A. N.] МОРДВИНОВ, А. H. 1992. Мохообразные центральной части Приволжской возвышенности (конспект фљоры). - [Bryophytes of Central Part of Cis-Volga Upland (conspect of flora)]. Нркутск, РАН, СО, Сиб. Ни-m фuswor. и Gиохимии растений. Деп. ВНННТН 28. II. 1992. No 667-B92 lIrkutsk, Ross. Akad. Nauk, Sib. Otd., Inst. Fiziol $i$ Biakhimii Rast. Msc. Resened VINITI 28. II. 1992, No 667 B921, 57.

[MULDIYAROV, Е. ҮA.] МУЛЬДИЯРОВ, Е. Я. 1990. Определитель листостебельных мхов Томской o6ractu. - [Handbook of mosses of Tomsk Provincel. Toмck, Н3d-60 Toмck. YH-ma [Tomsk, Izd. Tomsk Univ. J, 208.

[NAVROTSKAYA, $\quad$ I. L. \& L. YA. PARTYKA] НАВРОЦЬКА, І. Л., Л. Я. ПАРТИКА 1990. Лишайники $i$ мохи 3 Червоноі книти СРСР у Картатьскому державному природному національному парку. - [Lichens and moses of Red data Book of the USSR in Carpatian State Natural National Park]. Національмi napкu, ix багатофункцінальне значення $i$ проблеми охоронни приради (Тези доп. хонф., Яремча, 2630 вер. 1990) Яремча (Nazionalnye Parki, ith bagatofunkzionalne znachennya $i$ problemy okhoronny pryrody (Abstr. Conf., Yaremcha, 26-30 Sept. 1990). Yaremcha]: 55-56.

[NAVROTSKAYA, $I . \quad$ L. \& L. YA. PARTYKA] HАВРОЦbКА, I. Л., Л. Я. ПАРТИКА 1991. Ровиток ліхенологічних 1 бріологічних досліджень на Ухраіні. - [Lichenological and bryological investigations in Ukraine]. Yxp. Bom Журн. [Ukr. Bot. Zhurn.] 48(6): 50-60.

ORBAN, S. 1990. Coenological connections of the life strategies of bryophytes. - In. Schljakov, R. N. (ed.) Abstr. 7th Meeting Centr. \& East Europ. Bryol Working Group, Kirovsk - Apatity, 25-30 June 1990. Apatity, Acad. Sci. USSR, Kola Sci. Center, Polar-Alpine Bot. Garden: 49.

OTNJUKOVA, T. N. 1990. Synusiae moss-soil cover in the forest of Muiskaya Hollow (the Northern Zabaikalye). - In: Schljakov, R. N. (ed.) Abstr. 7th Meeting Centr. \& East Europ. Bryol. Working Group, Kirovsk - Apatity, 25-30 June 1990. Apatity, Acad. Sci. USSR, Kola Sci. Center, PolarAlpine Bot. Garden: \$9-50.

[PARIBOK, T., N. SASYKINA \& B. ZOLOTAREVA] ПАРИБОК, Т., Н. САСЫКИНА, Б. 3ОЛОТАРЕВА 1991. Содержание металлов в эпигейных мхах на загрязненных территориях. [Metal content in terricolous mosses in polluted areas]. Кзв. АН Эстонии, сер. Экология [Izv. Akad. Nauk Estonii, ser. Ekologia] 1 (4): 160-164.

[PARTYKA, L. YA.] ПАРТИKA, Л. Я. 1990. Поширення видів роду Rhodobryum (Schimp.) Limpr. на Украіні. - [Distribution of the genus Rhodobryum (Schimp.) Limpr. species in the 
Limpr. на Укpairi. - [Distribution of the genus Rhodobryum (Schimp.) Limpr. species in the Ukraine?. Укp. Bom. Журн. [Ukr. Bot. Zhurn.] $47(3): 28-31$.

[PARTYKA; L. ҮA.] ПАРTИKA, Л. Я 1990. Флорнстико-систематичний аналіз бріхфлорн Криму. - [Floristic and systematic analysis of the Crimean bryoflora]. Укp. Бот. Журк. [Ukr. Bot. Zhurr.] 47(1): 30-32.

PARTYKA, L. YA. 1990. Bryoflora of the Crimea and its peculiarity. - In. Schljakov, R. N. (ed.) Abstr. 7th Meeting Centr. \& East Europ. Bryol. Working Group, Kirovsk - Apatity, 25-30 June 1990. Apatity, Acad. Sci USSR, Kola Sci. Center, PolsuAlpine Bot. Garden: 50-51.

[PARTYKA, L. YA.] ПLAPTЫKA, Л. Я્्. 1991. Кавказские связи бриофлоры Крыма. [Caucasian relationships of bryoflora of Crimea]. Бриология в СССР, eе достихения $и$ перспективы (Маm. конф., Льеов, 10-12 сент. 1991) (ред. Демкив, О. Т.), ЛьөОв, АН СССР, AH YCCP (In: Demkiv, O. T. (ed.) Briologia $v$ SSSR, ee dostizheniya $i$ perspektivy (Proc. Conf., Lwov, 10-12 Sept. 1991). Lvov, Akad. Nauk SSSR \& Akad. Nauk Ukr. SSRJ: 160-I63.

[PARTYKA, L. ҮA.] ПАРТИКА, Л. Я. 1992. Рідкісні мохоподібні Криму. - [Rare bryophytes of Crimea], Уxp. Бот. Журн. [Ukr. Bot. Zhurn.] 49 (1): $55-59$.

[PARTYKA, L. YA.] [LAPTЫKA, Л.Я. 1992. Moxoo6pasныe. - [Bryophytes fof Karadag Reserve, Crimea)] Bодоросли, грибы, мохообразнье Карадагского заповедника (аннотированный список вuдDs) (Флоры и фауны заповедников СССР - ред. Соканов, В. Е., Т. М. Корнеева) М., Комиссия РАН по запов делу, НЭМЭЖ, СоцЭкол. Союз /Vodorosli, griby, mokhoobraznye Karadagskogo zapovednika (annotated list of species) (In: Sokolov, V. E. \& T. M. Korneewa (eds) Flory i fauny zapovednikov SSSR) Moscow, Ross. Akad. Nauk.. J: 55-63.

[PESHKOVA, G. I.] ПЕUUKOBA, Г. И. 1990. К фиоре печеночных мхов Калужской области. - [On hepatic nora of Kaluga Province]. Hooocmu Cucm. Huzu. Pacm. [Novasti Sist. Nizsh. Rast.] 27: 144147.

PESHKOVA, G. 1. 1990. Moss flora of Kaluzhskaya Region. - In: Schljakov, R. N. (ed.) Abstr. 7th Meeting Centr. \& East Europ. Bryol Working Group. Kirovsk - Apatity, 25-30 June 1990. Apatity, Acad. Sci. USSR, Kola Sci. Center, Polar-Alpine Bot. Garden: 52.

[POPOVA, N. N.] ПОПОВА, Н. Н. 1990. Брнофлора заповедника "Галичья пора" и его окрестностей. [Bryoflora of the State Reserve "Galichya Gora" and of its neighbouring lands]. Бот. Журн. [Bot. Zhurn. J 75(10): $1408-1420$.

[POPOVA, N. N.] ПОПОВА, Н. Н. 1990. Бриофлористические исследования заповедных территорий лесостепи. - [Bryofloristic investigations in protected areas in forest-steppe]. Заповедники СССР - ux настоямее и будущее, Часть II. Ботаника, лесоведение, понвенноце исследования (ред. Тихомиров, В. Н. и др.) (Тез.

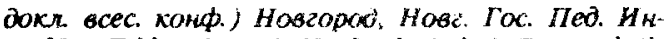
m IIn: Tikhomirov, V.N. \& aL (eds) Zapovedniki SSSR - ikh nastoyasshchee budushchee, II. Botanika, lesovedenie, pochwennye issledovaniya (Abstr. Conf.). Nougorod, Novgor. Gas. Pedag. Inst.]. $147-150$.

[POPOYA, N. N.] IIOHOBA. H. H. 1990. Генофонд бриофитов лесостепи не ег охрана. - [Genofond of bryophytes of forest-steppe and its protection]. Экологические проблемы охраны живой природж, У. I (ред. Красипов, В. А.) (Тез Докл Всесоюзн. Конф.) М., ВННИ Охр. ПТир. и Зап. Дела, АН CCCP и дp. (In' Krasilov, $\%$. A. (ed.) Ekologicheskie problemy okhrany shiwo prirody, I (Abstr. All-Union Conf.) Mascow, Ises. Nauchn-Issled. Inst. Okhrany Prirody i Zapow. Dela, Akad. Nauk SSSR \& al. I: 1 \$6-147,

[POPOVA, N. N.] IIOTIOBA, H. H. 1990. Mхн - KaK объехты стационарных исследований. в заповедниках. - [Mosses as an object of stational studies in reserves]. Haythibse uccredoearus $\theta$ запоедниках и принципо разработки региональных програн для заповедников лесной зоны еөропейской насти СССР (ред. Довганич, Я. Е., Т. М. Корнеева)(Тез докл. семинара, Paхов, 23-25 а82. 1990) Ужzopod [In: Dovganich, Ya. E. \& T. M. Korneeva) Nauchnye issledovaniya $v$ zapovednikakh i prinzipy razrabotki regionalnykh programm diya zapovednikov lesnoi zony evropeiskoi chasti SSSR (Abstr. Symp., Rachov, 23-25 Aug. 1990) Uzhgorod]: 85-88.

POPOVA, N. N. 1990 . Taxonomic structure of bryofloras of Physiogeographic regions of the Middle Russian Forest-Steppe. - In: Schljakov, $R$. N. (ed.) Abstr. 7th Meeting Centr. \& East Europ. Bryol. Working Group, Kirousk - Apatity, 25-30 June 1900. Apatity, Acad. Sci. USSR, Kola Sci. Center, Polar. Alpine Bot. Garden: 53.

[POPOVA, N. N. \& V. M. VIRCHENKO] MOMOBA, H. H., В. М. ВИРЧЕККО 1991. ФлорА мохообразных урочнщя Морозова гора. [Briophyte flora of Morozova Gora area] Природнье особенностиі заподедника "Галичья гора" (ред. Хмелев, К. Ф.) Воромеж, Изд. Boponeжck. Ун-ma /1n: KHmelev, $K$ Ph (ed.) Prirodnye osobennosti zapoved nika 'Galichya Gora". Voronezh, Izd. Voronezh Univ. 1: $\$ 0-49$.

[POPOVA, N. N. \& E. V. YYSHEGORODSKIKH] ПОПОВА,Н. H., Е. В. BНIIIEГОРОДСКИХ 1990. Бриофлора Соснинскоге ландшафтколо района Среднерусской лесостепн. - [Bryoflora of Sosninskii landscape region of Central-Russian Up. land forest-steppe]. AxmyarbHou eonpocos ботаники и экологин (Тез. докл хонф., Каменец-Подольский, 14-16 мах 1990) КаменеңПодольский (Aktualnye woprosy botaniki i ekologit (Abstr. Conf., Kamenez-Podolskii, 14-16 $\mathrm{Maj}$ 1990). Kamenez-Podolskii ]: 37-38.

[POPOVA, N. N. \& E. V. VYSHEGORODSKIKH] ПОПОВА,Н. Н., Е. В. ВЫНІЕГОРОДСКНХ 1991. Анализ флоры правобережь Верхней Оки - [Analysis of fora of rigth bank of Uppre Course of Oka River]. Бршология в СССР, ее достихения и перспективы (Мат. конф., ЛЬвов, 10-12 сент. 1991) (ред. Демкие, О. Т.), ЛьоОв, АН СССР, AH YCCP IIn: Demkiv, O. T. (ed.) Briologia $\vee$ 
\& Akad. Nauk Ukr. SSRJ: 164-168.

[POTEMKIN, А D.] ПОТЕМКИН, А. Д. 1990. Анализ модифнкационной нзменчивости печеночных мхов полустрова ямал. - [Analysis of modificational variability of hepatics of Yamal Peninsula] Труда 3 мол конф. ботиников Ленинграда, Ч. Ленинград, anp. 1990. Л., АН СССР, Бо⿴囗 Нн-m. Дen. ВИНИТИ 14. ХI. 1990, No 5700-B90/Trudy 3 molod. conf. bot. Leningrada, Pt. I. Leningrad, Apr. 1990. Leningrad, Akad. Nauk SSSR, Bot. Inst. Msc. Reserved VINITI 14. XI. 1990, No 5700B90) 1: 235-255.

[POTEMKIN, A. D.] ПОТЕМКИН, А. Д. 1990. Печеночные мхи полуострова Ямал. - [Hераtics of Yamal Peninsula]. Aemopeф. дисc.. канd. бuол. rayk $J ., A H$ CCCP, $B H H$ /Thesis Ph D. Leningrad, Akad. Nauk SSSR, Bot. Inst.], 16.

[POTEMKIN, A. D.] ПIОТЕMКИН, А. Д. 1990. Род Tritomaria (Нераticae, Lophoziaceae) на Ямале. [The genus Tritomaria (Hepaticae, Lophoziaceae) on the Yamal Peninsula]. Бom. Журн [Bot. Zhurn.] 75(12): 1742-1753.

[POTEMKIN, A. D.] ПOTEMKHH, А. Д. 1990. Lophozia alboviridis и $\mathrm{L}$. decolorans (Hepaticae) на Ямале. - [Lophozia alboviridis and L. decolorans (Hepaticae) on the Yamal Peninsula]. Bom. Жypн [Bot. Zhurn.] 75(8): 1086-1092.

[РОТЕMКIN, А. D.] ПОТЕМКИН, А. Д. 1990. Об изменчивости некоторых печеночных мхов из южных и арктических тундр полуострова Ямал. [On the variation of some hepatics from southern and arctic tundras of the Yamal Peninsula]. Hooacmu Cucm. Huзu. Pacm. INovosti Sist.Nizsh. Rast. / 27: 147-153.

POTEMKIN, A. D. 1990. The liverworts of the Yamal tundras. - In. Schljakov, R. N. (ed.) Abstr. 7th Meeting Centr. \& East Europ. Bryol. Working Group, Kirousk - Apatity, 25-30 June 1990. Apatity, Acad Sci. USSR, Kola Sci. Center, PolarAlpine Bot. Garden: 54-55.

[POTEMKIN, А. D.] ПОТЕМКИН, А. Д. 1991. О состоянии изученности н задачах по изучению семейства Aneuraceae в CССР. - [Current status of knowledge and problems of studies of family Aneuraceae in USSR]. Бpиология \& СCCP, ee достихения и перспехтивы (Мат. конф., Л 10-12 сент. 1991) (ред. Демкив, О. Т.), Львов, AH CCCP, AH YCCP (In. Demkiv, O. T. (ed.) Briologia y SSSR, ee dostizheniya $i$ perspektivy (Proc. Conf, Lvov, 10-12 Sept. 1991). Lvov, Akad. Nauk SSSR \& Akod. Nauk Ukr. SSRJ: 169-174.

[POTEMKIN, A. D.] ПОТЕМKИН, А. Д. 1992. Barbilophozia hyperborea (Schust.) Potemk. comb. nov. n Cephaloziella rubella (Nees) Warnst. var. arctogena Schust. в Советской Apктике. - [Barbilophozia hyperborea (Schust.) Potemk. comb. nov. and Cephaloziella rubella (Nees) Warnst. var. arctogena Schust. in Sovet Arctic] Hooocmu cucm. Husu. pacm. [Nowosti Sist. Nizsh. Rast.] 28: 148-155.

POTEMKIN, A. D. 1992. A new species of Prasanthus (Hepaticae, Gymnomitriaceae) from the Yamal Peninsula, West Siberian Arctic. - Ann Bot. Fennici 29(4): 319-323.

[POTEMKIN, A. D.] ПОТЕМКИН, А. Д. 1992.
Бесхлорофильный мнкотрофный печеночник Cryptothallus mirabilis (Aneuraceae. Hepaticae) no, Ленинградом. - IThe achlorophyllous mycotrophic liverwort Cryptothallus mirabilis (Aneuraceae, Hepaticae) in the neighbournood of [eningrad] Som Kурн. /Bot. Zhurn.] 77(1): 78-83.

[POTEMKIN, A. D.] ПОТЕМКИН, А. Д. 1993. О ннутрнвидовой таксономии, размножении и синонимике Scapania scandica (H. Am. et Buch) Macv. (по ямальским материалам). - IOn the infraspecific taxonomy, reproduction and synonymy of Scapania scandica (H.Arn. et Buch) Macv. (on the base of the Yamal materials)] Hooocmu cucm. низи. pacm. [Novosti Sist. Nizsh Rast.] 29: 153157.

[POTEMKIN, А. D.] ПОТЕМКИН, А. Д. 1993. О размножении некоторых печеночкиков. - [On the reproduction of some hepatics] Hooocmu cucm. ruзu. pacm. [Nowosti Sist. Nizsh Rast.] 29: 145152.

[POTEMKIN, A. D. \& 1. У. TCHEREPANOV] ПОТЕМКИН, А. Д., И. В. ЧЕРЕПАНОВ 1993. Х флоре печеночных мхов Лениградской области. Новые и малоизвестные для области таксоны. IOn the hepatic flora of the Leningrad Province. New and littie-known taxa for the province] Hoвоcmu cucm. Huзu. pacm. [Novosti Sist. Nizsh. Rast.] 29: 158-16.5.

[PREOBRAZHENSKAYA, E. I.] ПРЕOБPAЖEHCKAЯ, Е. И. 1990 . Радноустойчивость организмов. Соббщение VI. Надцарство Ядерные организмы, моховидные. - [Radio-tolerance of living beings. Report VI. Eukaryota, Bryophyta]. Асрофиз. ННH ВАСХHНJ Деп. ВНHИТН 12. III. 1990, $N$ 1323-B90 lieningrad, Agrofiziol. Nauchn.-IssL Inst. VASKHNIL Msc. Reserwed VINITI 12. III. 1990, No 1323-B90.J, 9.

RAICZY, M. \& B. PAPP 1990. An on-life catalogue of bryophyte type specimens in BP. - In. Schljakov, $R$. N. (ed.) Abstr. 7th Meeting Centr. \& East Europ. Bryol Working Group, Kirowk - Apatity, 25-30 June 1990. Apatity, Acad. Sci. USSR, Kola Sci. Center, Polar-Alpine Bot. Garden: 55.

[RAKHMATULINA, E. K.] PAXMATYJIHHA, Э. K. 1990. Мхи гербария Института бнологии АН Киргизской ССР. - [Mosses of Herbarium of Institute of Biology Acad. Sci. Kirgizian SSR]. H3a. AH КиргССР. Хин.-Технол. и биол науки /Izv. Akad. Nauk Kirg. SSR. Khim-Tekhn. \& Biol. Naukil \{4!: $48-56$.

[RECHAN, S. P., T. V. MALYSHEVA, A. B. ABATUROV \& P. N. MELANKHOLIN] PEYAH, C. П., T. B. MAЛЫШЕВA. А. B. АБАТУPOB, II. Н. МЕЛАІХОЛИН 1993. Леса северного IIодмосковья. - [Forests of the Northern Mosicow Province]. M., PAH, Нн-m Jlecoredenus Moscow. Ross. Akad. Nauk, Inst. Lesovedeniyal, 316.

[RIPETSKY, R. T.] РИПЕЦКИИ, Р. Т. 1991. Экспериментальные исследования А. C. Лазаренко и вопросы генезиса чередования поколений у моховидных. - [Experimental studies of A. S. Lazarenko and aspects of origin of altenation of generation in bryophytes]. Бриолосия в СССР, eе достихения $u$ nерспективь (Mam. конф., Лько, 10-12 сент. 1991) (ред. Демкия, 
конф., ЛЬвов, 10-12 сект. 1991) (ред. Демкив, O. T.), Jbsos, AH CCCP, AH УCCP (In: Demkiv, O. T. (ed.) Briologia v SSSR, ee dostizheniya i perspektivy (Proc Conf., Lwov, 10-12 Sept. 1991). LYov, Akad. Nauk SSSR \& Akad. Nauk I/kr. SSRl: 175-182.

RIPETSKY, R. T. \& N. A. KIT 1990. Apomyxis of mosses as a problem of developmental biology. - In: Schljakov, R. N. (ed.) Abstr. 7th Meeting Centr. \& East Europ. Bryol. Working Group, Kirousk - Apatity, 25-30 June 1990. Apatity, Acad. Sci. USSR, Kola Sci. Center, Polar-Alpine Bot. Garden: 56.

[RIPETSKY, R. T. \& N. A. KIT] РИПЕЦКИЙ, P. T., Н. А. КИТ 1992. Мхи хак обьект исследования детерминации развития. - [Mosses as an object for studies of ontogenesis determination]. Teз. Докr 2 Сьезда Всес. О-ва физиологов растений, Ч. II, Минск, 24-29 сент. 1990 Москөа, АН СССР, Bcec. O-во Физиол Pacm. [Abstr. 2 Congr. of AllUnion Soc. Plant Physiol. Pt. II, Minsk, 24-29 Sept. 1990. Mascow, Akad. Nauk SSSR, Vses. Obshch. Fiziol Rast. ]: 178.

RUSINSKA, A. 1990. Mosses of Island Seili in the Archipelago of Finland. - In: Schljakov, R. N. (ed.) Abstr. 7th Meeting Centr. \& East Europ. Bryol. Working Group, Kirovsk - Apatity, 25-30 June 1990. Apatity, Acad. Sci. USSR, Kola Sci. Center, Polar-Alpine Bot. Garden. 57.

[RYKOVSKY, G. F.] РЫКОВСКИЙ, Г. Ф. 1991. Генезіс пратанемы імхоу (Bryopsida) у сувязі 3 умовамі асяродизя. - [The origin of protonema in Bryopsida, in relarion to environments]. Becui $A H$ БCCP. Cep. Birr. Has. IVestsi Akad. Nav. Beloruss. SSR. Ser. Biyal. Nav.J (3): 49-54.

RYKOVSKY, G. F, 1990. The origin of bryophytes as a group of higher plants. - In: Schljakov, $R$. N. (ed.) Abstr. 7th Meeting Centr. \& East Europ. Bryol. Working Group, Kirovsk - Apatity, 25-30 June 1990. Apatity. Acad. Sci. USSR, Kola Sci. Center, Polar-Alpine Bot. Garden: 57-58.

[RYKOVSKY, G. F.] РЫКОВСКИЙ, Г. Ф. 1991. Полесье как хорологический рубеж для мохообразных. - [Polessye as a chorological limit for bryophytes]. Бриолоzия a СССР, eе достижения и перспективы (Мат. конф., Львов, 10-12 сент. 1991) (ред. Демкив, О. Т.), Льөов, AH CCCP, AH YCCP /In: Demkiv, O.T. (ed.) Briologia v SSSR, ee dostizheniya $i$ perspektivy (Proc. Conf., Lwov, 10-12 Sept. 1991). LWov, Akad. Nauk SSSR \& Akad. Nauk Ukr. SSR]: 182-18.5.

[RYKOVSKY, G. F.] РЫКОВСКИИ, Г. Ф. 1992. Цикл развития мохообразных и апомиксис [Life cycle of bryophytes and apomyxis] Ботаника. Нсследования (Минск) [Botanika. Issledovaniya \{Minsk\}/ 31: 183-19\}.

[SAKAUOVA, G. B.] CAKAYOBA, Г. Б. 1991 Материалы к флоре печеночных мхов Южного Arras. - [Contribution on the hepatic flora of South Altai]. Алма-Ата, АН КазССР, Ик-т Ботаники. Дen. КазНИИНТн 13. VI. 1991, No 3420-Ka9l IAlma-Ata, Akad. Nauk Kazakh. SSR, Inst. Bot. Msc. Reserved KazakhNIINTI 13. VI. 1991, No 3\$20-Ka 911, 7

[SAKAUOVA, G. B.] CAKAYOBA, Г. Б. 1991 Сфагновые мхи Кжного Aлtaя. - [Sphagna of
South Altai]. Arma-Ama, АН КазССР, Ин-m Ботаники Деп КазННHНТН 13. VI. 1991, No 342I-Ka9I /Alma-Ata, Akad. Nauk Kazaki. SSR, Inst. Bot. Msc. Reserved KazakhNIINTI 13. VI. 1991, No 3420-Ka 911, S.

[SAKAUOVA, G. B.] CAKAYOBA, r. . 1992. Mохоббразные Южнот Алтах - [Bryophytes of South Altai]. Asmopeф. дucc... канд. бuол наух Душанбе, AH Pесn Тадхикистан, Ннст Бот. IThesis Ph. D.. Dushanbe, Akad. Nouk. Resp. Tadjikistan, Inst. Bot.], 22

[SCHLJAKOV, R. N. (ed.)] ШUЯKOB, P. H. (ред.) 1990. Путеводитель экскурсий по Хибинским горам 7 междунар. совещ. бриологов Центр. и Вост. Европы, Кировск - Апатиты, 25-30 июня 1990. - [Excursion Guide in Khibiny Mountains for 7th International Conference of Bryologists of Central and Eastern Europe, Kirovsk-Apatity, 25-30 June 1990]. Anamumb, $A H$ CCCP, KHU, [Apatity, Akad. Nauk SSSR, Kol. Nauchn. Centr], 51 .

SCHLJAKOV, R. N. \& A. D. POTEMKIN 1990. The main features of the hepatic flora of the Arctic floristic region of the USSR. - In: Schljakov, $R$. N. (ed.) Abstr. 7th Meeting Centr. \& East Europ. Bryol. Working Group, Kirowsk - Apatity, 25-30 June 1990. Apatity, Acad. Sci. USSR, Kola Sci. Center, Polar-Alpine Bot. Garden: 61-62.

SCHMIDT, C. 1990. Aquatic bryophytic vegetation in the colline-montane zone of Westphalia, West Germany. - In: Schijakov, R. N. (ed.) Abstr. 7th Meeting Centr. \& East Europ. Bryol Working Group, Kirousk - Apatity, 25-30 June 1990. Apatity, Acad. Sci. USSR, Kola Sci. Center, Polar-Alpine Bot. Garden: 58-59.

SCHUSTER, R. M. 1990. Rates of evolution and times of differentiation of Arctic Hepaticae: some speculations. - In. Schljakoy, R. N. (ed.) Abstr. 7th Meeting Centr. \& East Europ. Bryol. Working Group, Kirowk - Apatity, 25-30 June 1990. Apatity, Acad. Sci. USSR, Kola Sci. Center, Polar-Alpine Bot. Gorden: 60 .

[SLUKA, Z. A.] CJIYKA, 3. А. 1990. Особенности бриофлоры лесопарка Кузьминки. - [Peculiarities of bryoflora of forest-park Kuzminki [Moscow\}]. Биол Hayku [Biol Nauki] (5): 84-90.

SLUKA, Z. A. 1990. Epiphytic mosses in park-forests of Moscow. - In. Schliakov, R. N. (ed.) Abstr. 7th Meeting Centr. \& East Europ. Bryol. Working Group, Kirousk - Apatity, 25-30 June 1990. Apatity, Acad. Sci. USSR, Kola Sci. Center, PolarAlpine Bot. Garden: $62-63$.

[SLUKA, Z. A. \& L. I. ABRAMOVA] CЛYKA, 3. A., Л. И. АБРАМОВА 1990. ВндовоЙ Состав местообитания мхов в лесопарке ПооронскоеСтреинево. - [Species composition and habitats of mosses - in forest-park Pokrovskoye-Streshnevo \{Moscow\}]. M., Биол Наукu. Дen ВННИТИ, No 2489-B90. [Moscow, Biol. Nauki. Msc. Reserved VINITI, No 2489-B90J, 23.

[SLUKA, Z. A. \& L. I. ABRAMOVA] CIYKA, 3. A., Л. И. АБРАМОВА 1991. Мхи городской части лесопарка Юг-Западный. - [Mosses of city part of forest-park Yugo-Zapadnyj \{Moscow\}]. M., Биoл. 
[Moscow, Biol Nauki. Msc. Reserved VINITI 18. IX. 1991, No 3730-B9II, 26.

[SMOLYANTTSKI, L. Y.] СМОЛЯНИЦКИЙ, Л. Я. 1991. К методихе экофизиологических исследовикй и трансплантации мохообразньс (метод монолитов). - [On the methodology of ecophysiological studies and transplanting of bryophytes (method of plant monoliths)]. Epuarozus a CCC.P, се достихения $и$ перспективы (Мат. конф., Ibeos, 10-12 сент. 1991) (ред. Демкив, О. Т.), Josos, AH CCCP, AH YCCP [In: Demkiv, O. T. (ed.) Briologia v SSSR, ee dostizheniya $i$ perspektivy (Prac. Conf. Lrov, 10-12 Sept. 1991). Lrov, Akad. Nauk SSSR \& Akad. Nauk Ukr. SSR]: 186188.

SOEDERSTROEM, L. 1990. Dynamics of some hepatios on decaying logs. - In. Schljakov, R. N. (ed.) Abstr. 7 th Meeting Centr. \& East Europ. Bryol Working Group, Kirows - Apatity, 25-30 June 1990. Apatity, Acad. Sci. USSR, Kola Sci. Center, PolarAlpine Bot. Garden: 63-64.

SYTNIK, K. M., O. T. DEMKIV, E. L. KORDYUM, E. M. NEDUKHA \& L. A. DANEVICH 1989. Calcium gradient in plant ceils with polarized growth in simulated microgravity. - Ady. Space Res. 9 (11): 4I44.

SZWEYKOWSKI, J. 1990 . Hepatic flora of the Tatry Mts. - a synthetic view. - In: Schljakov, R. N. (ed.) Abstr. 7th Meeting Centr. \& East Europ. Bryol Working Group, Kirowsk - Apatity, 25-30 June 1990. Apatity, Acad. Sci. USSR, Kola Sci. Center, Polar-Alpine Bot. Garden: 65.

SZWEYKOWSKI, J. 1990. Species concepts in hepatics. In: Schljakov, R. N. (ed.) Abstr. 7th Meeting Centr. \& East Europ. Bryol Working Group, Kirowsk Apatity, 25-30 June 1990, Apatity, Acad. Sci. USSR, Kola Scl. Center, Polar-Alpine Bot. Garden: 65-66.

TAN, B. C., W. R. BUCK \& M. S. IGNATOV 1990. On the Hymalayan Struckia $C$. Meull. and Russian Cephalocaldium Lazar. (Muxcl, Hypnaceae). - Lindbergia 16(3): 100-104.

[TEKKO, S.] TEKKO, C. 1991. Исследование мхов для бионнұикация распределения серы в Эстонин. - [Bioindication of sulphur distribution in Estonia using mosses]. Иза. AH Эсmoнun, сер. Эkonazus [Izv. Akad. Naut Estonii, ser. Ekologia] 1(4): $179-182$.

[TIZINI, 1.] ТНЗИНИ, и. 1991. Морфалогоанатомнчесхое кследование Buxbaumia aphylla Hedw. (Buxbaumiacenc, Musci). - [MorphoAnatomic study of Buxbaumia aphylla Hedw. (Buxbaumiaceae, Musci)]. Aamoped. ducc... камd. Guar rayx M., MTY IThesis Ph. D.. Moscow, Mask. Gos. Univ. J, 20.

TOWNSEND, C. C. 1991. Two mosses of interest in the Soviet Union. - J. BryoL 16(4): 648-649.

[TROZENKO, G. V.] ТPOLEHKO, Г. В. 1990. Мхи IIapтauckon лесопарка $r$. Сердловска. [Moeses of Shartashski] forest-park, Sverdlovsk City]. Эколого-флористические исследоеания по споровим растениям Урала (ред. Горчакоаский, II. Л.), Сердловск. АH СССР, УрO [In: Gorchatovky" P. L (ed.) Ekologo-floristicheskie issle- dovaniya po sporovym rasteniyam Urala. Suendlowsk, Akad. Nauk SSSR, Ural. Otd.J: 24-33.

[TROZENKO, G. V.] TPOLEHKO, Г. B. 1990, K бриофnope Illapтaшcхoro seconapk $r$. Crepunoncka. - [On the bryoflora of Shartashski] forest-park, Sverdlovsk City]. Ботаническue

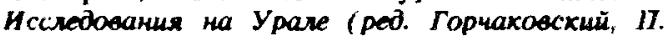
I.), Саердласк, АН СССР, УрО, Нн-т Экол Pастений и Жиеотных IIn: Gorchakorky, P. L. (ed.) Botanicheskie Issledowaniya na Urale. Swerdlowk, Akad. Nauk. SSSR, Ural. Otd.; Inst. Ekol Rast. $i$ Zhivotnykh]: 109.

[TSEGMED, TS.] ЦЭГМЭД, Ц. 1991. Распределение листостебельных мхов по поясам и типвм растительностя в горных системах Хархира и Typroн (MHP). - [Distribution of mosses along altitudinal zone and vegetation types in mountain Kharkhira and Turgaen (Mongolia)]. Бот. Журн. [Bot. Zhurn] 76(3): $108-111$.

[TSEGMED, TS.] ЦЭГМЭД, Ц. 1991. Географический анализ флоры листостебельных мхов Ханганскопо rорного массив (МНP). - [Geographical analyas of moes flora of Khangai Mountains (Mongolia)] Бот. Журн. [Bot. Zhurn.] 76(2): 280-286.

ULVINEN, T. 1990. The elements of the bryoflora of Kuusamo Area. - In: Schljakov, R. N. (ed.) Abstr. 7th Meeting Centr. \& East Europ. Bryol. Working Group, Kirowsk - Apatity, 25-30 June 1990. Apatity, Acad. Sci. USSR, Kola Sci. Center, PolarAlpine Bot. Gorden: 66-67.

[ULYCHNA, К. О.] УЛЫЧНА, К. O. 1990. Брналогнческий гербарий. Семейства Ptychomitriaceae, Cryphaeacese, Hypopterygiaceae и Fabroniaceae. - [Bryological Herbarium. Families Ptychomitriaceae, Cryphaeaceae, Hypopterygiacese and Fabroniacene]. Kamanoz жузейных фондов (ped. Ктимишия, А. С.), Льөов, АН УСС., Гос. Природоведиеский Музей УССР /In Klimishin, A. S. (ed.) Katalog muzeinykh fondov. Lvov, Akad. Nauk Ukr. SSR, Gos. Prirodowedcheskij MuseiJ: 4549.

[ULYCHNA, К. О.] УЛЫЧНА, К. О. 1991. О пронсхождении ножки гаметантя мхов (Bryopsida). - [On the origin of the stalk of cametangia of Bryopsida]. Epuorozus a CCCP, ee достихения и перспективы (Мат. конф., Льөая, 10-12 сент. 1991) (ред. Демкия, О. Т.), ЛЬо, AH CCCP, AH YCCP [In: Demkiv, O. T. (ed.) Briologia v SSSR, ee dostizheniya $i$ perspektivy (Pruk Conf., Lwov, 10-12 Sept. 1991). Lwov, Akad. Nauk SSSR \& Akad. Nauk Ukr. SSR/: 189-191.

[VANA, J, \& M. S. IGNATOV] BAHЯ, П, M. C. ИГНАТОВ 1990. Печеночники Холодной Речки (A6xasckax CCP). - [Hepatics of Kholodnaya Reczka (Abkhazskaya ASSR)]. Brond. Гrask Бom. Cada /Bull. Glavn. Bot. Sadal 155: 43-44.

VARGA, J. 1990. Collembola communities of some mose species. - In: Schljakov, R. N. (ed.) Abstr. 7th Meeting Centr. \& East Europ. Bryol Working Group, Kirowsk - Apatity, 25-30 June 1990. Apatity, Acad. Sci. USSR, Kola Sci. Center, PolarAlpine Bot. Ganden: 67.

VASILYEV, A. N. 1990. Bryophyta of the Central Part of Southern Siberia. - In: Schljakov, R. N. (ed.) 
Abstr ?h Meeting Centr. \& East Europ. Bryol. Working Group, Kirousk - Apatity, 25-30 June 1990. Apority, Acad. Soi USSR, Kola Sci. Center, Polar-Alpinc Bot. Garden 64

[VASILYEV A. N.) BACKJbEB, A. H. 1091 Ђнолюниеский анализ бриофлоры Иетральной насти Кжной Сибкри. - [Biological anaiysis of bryoflora of Central Part of South Siberiaj. вриология в СССР, ее достихения и nерспектияы (Mam. конф., ЛЬөов, 10-12 сент. 1991) (ред. Демкив, О. Т.), ЛЬв०в, АН СССР, AH YCСP IIn: Demkiv $O$. T. (ed.) Brioloya v SSSR, ee dostizheniya $i$ perspektivy (Proc. Conf., Lwov, 10-12 Sept. 1991). Lwov, Akad. Nauk SSSR \& Akad. Nauk Ukr. SSR ]: 39-41.

[VILDE, R. O.] ВИЛЬДЕ, Р. O. 1990. Рacnpoстранение жизненных форм мхов в зависимости or условий местообитаний. - [Distribution of living formis of moses in relation to their habitats]. Hoexcmu Cucm. Husu. Pacm. [Novasti Sist. Nizsh. Rast. ] 27: $128-140$.

[VIRCHENKO, V. M.] ВНPYEHKO, В. М. 1990. Бриофлора лесопарковой зоны г. Киева. [Bryoflora of forest-park zone Kiev City]. Ахтуальные вопросы ботанихи и экологии. (Тез. докл. конф., Каменец-Подольский, 14-16 мая 1990) Каменец-Подольский, Aktualnye voprosy botaniki i ekologii (Abstr. Conf., Kamenez-Podolskii, 14-16 May 1990). Kamenez-Podolskii]: 29-30.

[VIRCHENKO, V. М.] ВИРЧЕНКО, В. М. 1990. ПрО мохоподібні м. Киева 1 йото окалиць. - [On bryophytes of Kiev and its surroundings]. $Y_{x p}$. Bom. Жури. [Ukr. Bot. Zhurn.] 47(2): 24-27.

VIRCHENKO, V. M. 1990. Species of the section Erythrocarpa Kindb. of the genus Bryum Hedw, in the Ukrainian SSR. - In. Schljakov, R. N. (ed.) Abstr. 7th Meeting Centr. \& East Europ. Bryol. Working Group, Kinowk - Apatity, 25-30 June 1990. Apatity, Acad. Sci. USSR, Kola Sci. Center, PolarAlpine Bot. Garden: 69-70.

[VIRCHENKO, V. М.] ВИРЧЕНКО, В. М. 1991. Бриофлора лесопарковой зоны Г. Киева и ее изменение за последние 100 лет. - [Bryoflora of forest-park zone of Kiev City and its changes within the recent hundred years]. Брuолozus a CCCP, ee доспихения и перспектияы (Мат. конф., ЛЬеов, 10-12 сент. 1991) (ред. Демкив, О. Т.), ЛЬАов, AH CCCP, AH YCCP (In. Demkiv, O. T. (ed.) Briologia y SSSR, ee dostizheniya $i$ perspektivy (Proc. Conf., Lyov, 10-12 Sept. 1091). Lwov, Akad. Nauk SSSR \& Akad. Nauk Ukr. SSRl: 42-46.

[VIRCHENKO, צ. M.] ВИРЧEHKO, В. М. 1991. Зміни в бріoфsopi Даринцьком лісонарку (м. Киів) 3a останні 100 років. - [Changes in bryoflora of the Darnitsa forest-Park (Kiev) in the last hundred years]. Укp. Боm. Жyрн [Ukr. Bot. Zhurn.] $48(1): 44-49$.

[VIRCHENKO, У. M.] BИРЧEHKO, B. М. 199 ! Eпiфiтнi бріофіти зеленоі жони м. Львова. [Epiphytic bryophytes of the green belt of l,vov] Ахтуальні проблеми аивчення фітобіоти західних реzіонія Ухраіяи (Мат. Конф., JІьвів, 2-5 квітня 1990) (реd. Kazaro, О. О., Н. М. Cичак) Jbaia, Jbaia. Bid. Ih-my bom. AH УРCP, I bails. Держ. Ун-m /In: Kagalo, O. O\& N. M. Sy- chak (ed.). Aktualni problemy vyuchennya fitobioty zakhidnykh regioniv Ukrainy (Proc. Conf., Lviv, 2-5 Apr. 1990) Lviv, L.viv. Vid. Inst. Bot. Akad. Nauk Ukr. RSR \& Lviv. Dersh Univ. 1: 24-26.

[VIRCHENKD, V. M.] BUPYEHKO, B. M. 1991. Нypnum pratense Koch ex Spruce y 6pioфлорі Ухраiни. - [Hypnum pratense Koch ex Spruce in bryoflora of Ukrainel. Jxp. Bom. Журн. [Ukr. Bot. Zhurn.] 48(5): $105-106$.

[VIRCHENKO, V. М.] ВИРЧEHKO, В. М. 1992. Нова 6ріологічна література. - [New bryological literature]. Укp. Born. Журн. [Ukr. Bot. Żhurn.] 49(2): $105-107$.

[VIRCHENKO, V. M.] BИPपEHKO, D. M. 1992, ЧH знайдено Atractylocarpus alpinus (Schimp. ex Milde) Lindb. на $\mathrm{Y}_{\mathrm{kpaini}}$ ? - IIs Atractylocarpus alpinus (Schimp. ex Milde) Lindb. found in Ukraine?]. Укp. Bom Xypk [Ukr. Bot. Zhurn] $49(3)$ : $95-98$.

VIRTANEN, R. J. 1990. Bryology of Kilpisjaervi area, NW Finnish Lapland. - In. Schljakov, R. N. (ed.) Abstr. 7th Meeting Centr. \& East Europ. Bryol. Working Group, Kirowsk - Apatity, 25-30 June 1990. Apatity, Acad. Sci USSR, Kola Sci. Center, Polar-Alpine Bot. Garden: 70-7I.

[VYSHEGORODSKIKH, E. V.] ВЫШЕГОРОДСКИХ, Е. В. 1990. Бриофлора Думчимскопо массива Орловской области. - [Eryoflora of Dumchimskij Area in Orel Provincel. Воронеж, Воронехск. ун-m Ren. ВНHИТН 20. IV. 1990, No 2135-B90 [Vononezh, Voronezh. Univ. Msc. Reserved VINITI 20. IV. 1990, No 2135-B90 J, 10.

VJÚNOVA, G. V. 1990. Comparison of local floras of the South-West of Leningrad Region. - In: Schljakov, $R$. N. (ed.) Abstr. 7th Meeting Centr. \& East Europ. Bryol Working Group, Kirowsk - Aparity, 25-30 June 1990. Apatity, Acad. Sci. USSR, Kola Sci. Center, Polar-Alpine Bot. Garden: 72.

[VYUNOVA, G. V.] BbHHOBA, Г. B. 1991. Материалы к брнофлоре Камчатки. [Contributions to bryoflora of Kamtachatka]. Бриология в СССР, eе орхтихения перспективы (Маm конр., Льов, 10-12 сент. 1991) (ред. Демкив, О. Т.), ЛЬ60s, АН СССР, AH YCCP (Jn Demkiv, O.T. (ed.) Briologia $v$ SSSR, ee dostizheniya i perspektivy (Proc. Conf., Lwov, 10-12 Sept. 1991). Lwov, Akad. Nauk SSSR \& Akad. Nauk Ukr. SSR /: 47-51.

WIEHLE, w. 1990. Cryptothallus on the Kola Peninsula. - In. Schljakov, $R$ N. (ed.) Abstr. 7th Meeting Centr. \& East Europ. Bryol Working Group. Kirowk - Apatity, 25-30 June 1990. Apatity, Acad. Sci. USSR, Kola Sci. Center, Polar-Alpine Bot. Garden: 72-73.

WIEHLE, W. 1990. Spherical mosses in the Khibiny Mountains, Kola Peninsula. - In: Schljakon, R. $N$. (ed.) Abstr. 7th Meeting Centr. \& East Europ. Bryol. Working Group, Kirowsk - Apatity, 25-30 June 1990. Apatity, Acad. Sci. USSR, Kala Sci. Center, Polar-Alpine Bot. Garden: 73-74.

WOJTUN, B. 1990. Nutrients in ombrotrophic Sphagna: patterns in species and elements. - In: Schljakov, $R$. N. (ed.) Abstr. 7th Meeting Centr. \& East Europ. Bryol. Working Group, Kirowk - Apatity, 25-30 
June 1990. Apatity, Acad. Sci. USSR, Kola Sci. Center, Polar-Alpine Bot. Garden: 74-76.

[YUKONENE, I. P.] ЮKOHEHE, И. П. 1991. Состояние изученности бриофлоры Литвы. [Current status of knowledge of bryoflora of Lietuva]. Бриология в СССР, еe достихения и перспективн (Mат. конф., Львов, 10-12 сент. 1991) (ред. Демкия, О. Т.), Льеов, АН СССР, AH YCCP IIn: Demkiv, O. T. (ed.) Briologia $v$ SSSR, ee dostizheniya i perspektivy (Proc. Conf., Lvov, 10-12 Sept. 1991). Luov, Akad. Nauk SSSR \& Akad. Nauk Ukr. SSR J: 201-204.

YURKOVSKAYA, T. K. 1990. The regional and local features of the flora of leafy mosses in north taiga mires in European Part of the USSR. - In. Schljakov, R. N. (ed.) Abstr. 7th Meeting Centr. \& East Europ. Bryol. Working Group, Kirowsk - Apatity, 25-30 June 1990. Apatity, Acad. Sci. USSR, Kola Sci. Center, Polar-Alpine Bot. Garden: 76-77.

[YURKOVSKAYA, T. K. \& L. A. VOLKOVA] ЮРКОВСКАЯ, Т. К., Л. А. ВОЛКОВА 1990. Особенности флоры листостебельных мхов болот европейской северной тайги. - [Peculiarities of flora of mosses of bogs of European Northern taigal. Hosocmu Cucm. Husu. Pacm. [Novosti Sist. Nizsh. Rast.] 27: 157-162.

ZANTEN, B. O. van 1990. The threat of extinction of some Dutch mosses. - In: Schljakov, R. N. (ed.) $A b$ str. 7th Meeting Centr. \& East Europ. Bryol Working Group, Kirowsk - Apatity, 25-30 June 1990. Apatity, Acad. Sci. USSR, Kola Sci. Center, Polar-Alpine Bot. Garden. 77.

[ZHELEZNOVA, G. V.] XEJE3HOBA, Г. В. 1990. Мохообразные антропогенных местообитаний в Kоми ACCP. - [Bryophytes of anthropogenic habitats in Komi ASSR]. Влияние антропогенных факторов на флору и растительность Севера (Труды Коми НЦ УрО АН СССР, No 108) (ред. Козубов, Г. М.), С (кхтывкар, АН СССР, УрО, KHU IIn: Kozubov, G. M. (ed.) Vliyanie antropogennykh faktorov na floru $i$ rastitelnast Severa (Trudy Komi Nauchn. Zentra Ural. Otd. Akad. Nauk SSSR, No 108). Syktyvkar, Akad. Nauk SSSR, UraL Otd., Komi Nauchn. Centr]: 15-27.

[ZHELEZNOVA, G. V.] ЖЕЛЕЗНОВA, Г. В. 1990. Листостебельные мхи Северного Урала на юговостоке Коми ACCP. - [Mosses of the Northern Ural within South-East of Komi ASSR]. Ботанические Нсследования на Урале (ред. Горчаковский, П. Л.), Сөердловск, АН СССР, УрО, Ин-m Экол Растекий и Животнах /In. Gorchakowky, P. L (ed.) Botanicheskie Issledovaniya na Urale. Sverdlows, Akad. Nauk SSSR, Ural. Otd., Inst. Ekol Rast. i Zhiwotnykh]: 31.
ZHELEZNOVA, G. V. 1990. Leafy mosses of the Komi ASSR. - In. Schljakov, R. N. (ed.) Abstr. 7th Meeting Centr. \& East Europ. Bryol Working Group, Kirovsk - Apatity, 25-30 June 1990. Apatity, Acad. Sci. USSR, Kola Sci. Center, PolarAlpine Bot. Garden: 78.

[ZHELEZNOVA, G. V.] ЖЕЛEЗHOBA, Г. B. 1991. Географический анализ видового состава листостебельных мхов Коми АССР. [Geographical analysis of moss species composition of Komi ASSR]. Бриология 8 CСCP, ee достихения и перспективы (Мат. конф., Львов, 10-12 сент. 1991) (ред. Демкив, О. Т.), Львов, AH CCCP, AH YCCP (In: Demkiv, O. T. (ed.) Briologia y SSSR, ee dostizheniya $i$ perspektivy (Proc. Conf., Lrov, 10-12 Sept. 1991). Lvov, Akad. Nauk SSSR \& Akad. Nauk Ukr. SSRJ: 87-90.

[ZHELEZNOVA, G. V.] ЖЕЛЕЗНОВA, Г. В. 1992. Листостебельные мхи южной части бассейна р. Печора. - [Mosses of southern part of Pechora River Basin] Флора и растительность южной части бассейна р. Печора (Труды Коми НЦ УрО PAH, No 126) (ред. Мартыненко, В. А.) Сыкmbeкар, РАН, УрО, КНЦ, Ин-т Биол /In: Martynenko, V. A. (ed.) Flora i Rastitelnost Yuzhnoi Chasti Basseina r. Pechora (Trudy Komi Nauchn Zentra UraL Otd. Ross. Akad. Nauk, No 126). Syktyvkar, Ross. Akad. Nauk, Ural. Otd., Komi Nauchn. Centr, Inst. Biol.]: 43-51.

ZYKOV, I. V. 1990. Preliminary results of Bryoflora study in Kalinin Region (the Upper Volga). - In. Schljakov, $R$. N. (ed.) Abstr. 7th Meeting Centr. \& East Europ. Bryol. Working Group, Kirousk - Apatity, 25-30 June 1990. Apatity, Acad. Sci. USSR, Kola Sci. Center, Polar-Alpine Bot. Garden: 79-80.

[ZYKOV, I. V.] ЗЫКОВ, И. В. 1991. Аннотированный список мохообразных Тверской области. Печеночники: Pseudolepicoleaceae - Cephaloziellaceae. - AAnnotated list of bryophytes of Tver Province. Hepatics: Pseudolepicoleaceae Cephaloziellaceae]. Флора и растительность Южной Тайси (ред. Смирнов, А. В.), Теерь, Tверской ун-m (In. Smirnov, A. V. (ed.) Flora $i$ rastitelnost Yuzhnoi Taigi. Tver, Tver. Univ. I: 4347. 